\title{
Asian Consensus Report on Functional Dyspepsia
}

\author{
Hiroto Miwa, ${ }^{1}$ Uday C Ghoshal, ${ }^{2}$ Sutep Gonlachanvit, ${ }^{3}$ Kok-Ann Gwee, ${ }^{4}$ Tïng-Leong Ang, ${ }_{1}^{5}$ Full-Young Chang, ${ }^{6}$ Kwong Ming \\ Fock, ${ }^{5}$ Michio Hongo, ${ }^{7}$ Xiaohua Hou, ${ }^{8}$ Udom Kachintorn, ${ }^{9}$ Meiyun Ke, ${ }_{10}^{10}$ Kwok-Hung Lai, ${ }_{11}^{11}$ Kwang Jae Lee, ${ }^{12}$ Ching-Liang Lu, ${ }^{6}$ \\ Sanjiv Mahadeva, ${ }^{13}$ Soichiro Miura, ${ }^{14}$ Hyojin Park, ${ }^{15}$ Poong-Lyul Rhee, ${ }^{16}$ Kentaro Sugano, ${ }^{17}$ Ratha-korn Vilaichone, ${ }^{18}$ Benjamin \\ CY Wong ${ }^{19}$ and Young-Tae Bak ${ }^{20 *}$
}

\begin{abstract}
${ }^{1}$ Division of Upper Gastroenterology, Department of Internal Medicine, Hyogo College of Medicine, Hyogo, Japan; ${ }^{2}$ Department of Gastroenterology, Sanjay Gandhi Postgraduate Institute of Medical Sciences, Lucknow, India, ${ }^{3}$ Department of Internal Medicine, Chulalongkorn University, Bangkok, Thailand; ${ }^{4}$ Department of Medicine, Yong Loo Lin School of Medicine, National University of Singapore, Singapore, ${ }^{5}$ Department of Gastroenterology, Changi General Hospital, Singapore; ${ }^{6}$ Division of Gastroenterology, Taipei Veterans General Hospital, National Yang-Ming University School of Medicine, Taipei, Taiwan; ' Department of Comprehensive Medicine, Tohoku University Hospital, Sendai, Japan; ${ }^{8}$ Division of Gastroenterology, Union Hospital of Tongii Medical College, Huazhong University of Science and Technology, Wuhan, China; ${ }^{9}$ Siriraj Hospital, Mahidol University, Bangkok, Thailand; ${ }^{10}$ Department of Gastroenterology, Peking Union Medical College Hospital, Chinese Academy of Medical Sciences and Peking Union Medical College, Beijing, China, ${ }^{11}$ Division of Gastroenterology, Kaoshiung Veterans General Hospital, National Yang-Ming University, Kaoshiung, Taiwan; ${ }^{2}$ Department of Gastroenterology, Ajou University School of Medicine, Suwon, Korea; ${ }^{13}$ Department of Medicine, University of Malaya, Kuala Lumpur, Malaysia; ${ }^{14}$ Department of Internal Medicine, National Defense Medical College, Saitama, Japan; ${ }^{15}$ Department of Gastroenterology, Gangnam Severance Hospital, Yonsei University College of Medicine, Seoul, Korea; ${ }^{16}$ Department of Gastroenterology, Samsung Medical Center, Sungkyunkwan University School of Medicine, Seoul, Korea; ${ }^{17}$ Department of Internal Medicine, Jichi Medical University, Tochigi, Japan; ${ }^{18}$ Gastroenterology Unit, Department of Medicine, Thammasat University Hospital, Pathumthani, Thailand; ${ }^{19}$ Department of Medicine, University of Hong Kong, Hong Kong, China; and ${ }^{20}$ Department of Gastroenterology, Korea University Guro Hospital, Seoul, Korea
\end{abstract}

\section{Background/Aims}

Environmental factors such as food, lifestyle and prevalence of Helicobacter pylori infection are widely different in Asian countries compared to the West, and physiological functions and genetic factors of Asians may also be different from those of Westerners. Establishing an Asian consensus for functional dyspepsia is crucial in order to attract attention to such data from Asian countries, to articulate the experience and views of Asian experts, and to provide a relevant guide on management of functional dyspepsia for primary care physicians working in Asia.

\section{Methods}

Consensus team members were selected from Asian experts and consensus development was carried out using a modified Delphi method. Consensus teams collected published papers on functional dyspepsia especially from Asia and developed candidate consensus statements based on the generated clinical questions. At the first face-to-face meeting, each statement was reviewed and e-mail voting was done twice. At the second face-to-face meeting, final voting on each statement was done using keypad voting system. A grade of evidence and a strength of recommendation were applied to each statement according to the method of the GRADE Working Group.

\section{Results}

Twenty-nine consensus statements were finalized, including 7 for definition and diagnosis, 5 for epidemiology, 9 for pathophysiology and 8 for management. Algorithms for diagnosis and management of functional dyspepsia were added.

\section{Conclusions}

This consensus developed by Asian experts shows distinctive features of functional dyspepsia in Asia and will provide a guide to the diagnosis and management of functional dyspepsia for Asian primary care physicians.

\section{(J Neurogastroenterol Motil 2012;18:150-168)}

Key Words

Asia; Diagnosis; Epidemiology; Functional dyspepsia; Management; Pathophysiology

Received: September 27, 2011 Revised: October 25, 2011 Accepted: October 29, 2011

(c) This is an Open Access article distributed under the terms of the Creative Commons Attribution Non-Commercial License (http://creativecommons. org/licenses/by-nc/3.0) which permits unrestricted non-commercial use, distribution, and reproduction in any medium, provided the original work is properly cited.

This report is published simultaneously in the Journal of Gastroenterology and Hepatology (volume 27, pages 626-641) and may be referenced under either journal).

*Correspondence: Young-Tae Bak, MD

Department of Gastroenterology, Korea University Guro Hospital, 148 Gurodong-ro, Guro-gu, Seoul 152-703, Korea

Tel: +82-2-2626-1778, Fax: +82-505-115-1778, E-mail: drbakyt@korea.ac.kr

Financial support: None.

Conflicts of interest: None. 


\section{Introduction}

Dyspepsia is one of the most common disorders in medicine, with dyspeptic patients seen on a daily basis not only by gastroenterologists but also by physicians in a variety of other fields. However, organic causes are found in only a minority of such patients. Functional dyspepsia (FD) is defined as a condition in which upper abdominal symptoms occur in the absence of organic disease that explains them. There are many FD patients in Asian as well as Western countries. The scientific investigation of the pathophysiology of FD began only recently and its first definition was developed in $1988 .{ }^{1}$ Since then, many of the ideas on this condition have been derived from studies conducted in Western societies, despite the large number of FD patients in Asian populations and much important research from Asian countries.

Accordingly, the establishment of an Asian consensus for FD is crucial in order to attract attention to such data from Asian countries, to articulate the experience and views of Asian experts, and to provide a relevant guide to the management of this disease for primary care physicians working in Asia. In particular, environmental factors such as food, lifestyle and prevalence of Helicobacter pylori infection are widely different in Asian countries compared to the West, and physiological functions and genetic factors of Asians may also be different from those of Westerners. Therefore, the Asian perspective should be useful for further understanding the pathogenesis of FD.

The understanding of FD is progressing and will evolve over time. We have summarized the current Asian perspective on FD in this consensus report, which will be revised as our understanding of FD grows.

\section{Methods}

The Asian Neurogastroenterology and Motility Association (ANMA) and the Asian Pacific Association of Gastroenterology (APAGE) agreed to jointly generate an Asian consensus report on FD and organized 4 teams for that purpose: Team 1, definition and diagnosis; Team 2, epidemiology; Team 3, pathophysiology; and Team 4, management. Twenty-two consensus team members were recruited from Asian countries on the basis of each member's scientific activities and published papers on FD.

The consensus development process was carried out by using a modified Delphi method. ${ }^{2}$ Consensus team members started their job in late June 2009 by collecting original papers on FD from Asian countries until the end of August 2009 through available global and domestic online literature searching systems. Papers in English and other languages that were not available online were searched manually. Thereafter the remaining important original and review papers not only from Asia but also from rest of the world were also collected and added. When a new paper was published during the consensus process, it was also included. After thorough reviewing of the literature, each team generated approximately 10 consensus statements through intra- and inter-team e-mail discussions, resulting in a total of 37 candidate consensus statements.

On September 19, 2010, the first Asian FD consensus meeting was held in Kuala Lumpur, Malaysia. At the meeting, each candidate statement was discussed in depth, and afterward, the statements were reviewed again and amended by the 4 teams, taking the discussions held at the first consensus meeting into consideration. At this point, 34 consensus statements had been developed.

The first e-mail voting on the consensus statements was done by all of the consensus members on October 26, 2010. Each member was asked to choose one of the following 6 levels of agreement on each statement (Table): (a) accept completely, (b) accept with minor reservation, (c) accept with major reservation, (d) reject with major reservation, (e) reject with minor reservation, and (f) reject completely. Consensus members were also asked to add comments on each statement, if any. When the proportion of members who voted (a) or (b) was $80 \%$ or higher, the statement was regarded as acceptable and a consensus was considered to have been reached. In the first e-mail vote, 25 of the 34 statements $(73.5 \%)$ were acceptable and the remaining 9 statements $(26.5 \%)$ failed to reach the consensus level.

After extensive discussions and subsequent revision of the consensus statements, the second e-mail voting was done on 35 statements on January 11, 2011. From this voting, 30 statements (85.7\%) were acceptable while 5 statements (14.3\%) were unacceptable. Each statement was reviewed and amended again by each team, and a total of 32 consensus statements were developed for final voting.

On March 3, 2011, the second Asian FD consensus meeting was held in Beijing, China. At the plenary meeting, voting on each statement was done using a keypad voting system. After each vote, a discussion was held, and if necessary, the statement was revised and voted on again until a consensus was reached. At 
Table. Grade of Evidence, Level of Agreement and Strength of Recommendation

\begin{tabular}{ll}
\hline \multicolumn{1}{c}{ Category } & \multicolumn{1}{c}{ Description } \\
\hline $\begin{array}{l}\text { Grade of evidence } \\
\text { High }\end{array}$ & $\begin{array}{l}\text { Further research is unlikely to change our confidence in the estimate of effect } \\
\text { Further research is likely to have an important impact on our confidence in the estimate of effect and might change } \\
\text { the estimate } \\
\text { Further research is very likely to have an important impact on our confidence in the estimate of effect and is likely }\end{array}$ \\
Low & An change the estimate \\
Very low & Accept completely \\
Level of agreement & Accept with minor reservation \\
a & Accept with major reservation \\
b & Reject with major reservation \\
$\mathrm{d}$ & Reject with minor reservation \\
$\mathrm{e}$ & Reject completely \\
$\mathrm{f}$ & A judgment that most well-informed people would make \\
Do it & A judgment that a majority of well-informed people would make but a substantial minority would not \\
Probably do it & A judgment that a majority of well-informed people would make but a substantial minority would not \\
Probably not do it & A judgment that most well-informed people would make \\
Not do it &
\end{tabular}

${ }^{a}$ Each statement was accepted when $80 \%$ or more of participants voted a or b.

the conclusion of this process, 29 consensus statements ( 7 on definition and diagnosis, 5 on epidemiology, 9 on pathophysiology and 8 on management) had been finalized. A grade of evidence and a strength of recommendation were applied to each statement according to the GRADE Working Group (Table). ${ }^{3}$ Algorithms for diagnosis (Fig. 1) and management (Fig. 2) of FD were made after the statements had been finalized.

\section{Consensus Statements}

\section{Definition and Diagnosis}

Statement 1. Dyspepsia refers to a symptom or set of symptoms that is (are) considered to originate from the gastroduodenal region. The dyspeptic symptoms are epigastric pain, epigastric burning, postprandial fullness, early satiation and others, including bloating in the upper abdomen, nausea, vomiting and belching.

Grade of evidence: not applicable.

Level of agreement: a: $89.5 \%$; b: $5.3 \%$; c: $5.3 \%$; d: $0 \%$; e: $0 \%$; f: $0 \%$.

For this statement, the consensus members decided to follow the concept of the Rome III Committee that dyspepsia is a symptom or a group of symptoms that is (are) considered to originate from the gastroduodenal region. ${ }^{4}$

However, the consensus members agreed to include upper abdominal bloating which is a common FD symptom. Although there are limited data on the prevalence of upper abdominal bloating in FD in Asia, most of the consensus members felt that this symptom is very common in Asian dyspeptic patients. It was reported that bloating was present in about half of the dyspeptic patients in the United States ${ }^{5,6}$ and was most common in patients with dysmotility-like dyspepsia. ${ }^{5}$ Studies in Korea and Japan demonstrated that postprandial distress syndrome (dysmotilitylike dyspepsia) was present in $69.9 \%$ and $81.3 \%$ of patients with dyspepsia, ${ }^{7}$ respectively. The overlapping of $\mathrm{FD}$ with other gastrointestinal (GI) motility disorders is common in Asia. It was reported that about one fourth of FD patients in China had overlapping irritable bowel syndrome (IBS). ${ }^{8}$

Statement 2. Functional dyspepsia is a condition characterized by chronic dyspeptic symptoms in the absence of organic, systemic or metabolic condition(s) that is (are) likely to explain the symptoms (see Fig. 1).

Grade of evidence: not applicable.

Level of agreement: a: $89.5 \%$; b: $10.5 \%$; c: $0 \%$; d: $0 \%$; e: $0 \%$; f: $0 \%$.

The consensus members agreed that chronic dyspeptic symptoms could be continuous, intermittent or recurrent. However, 


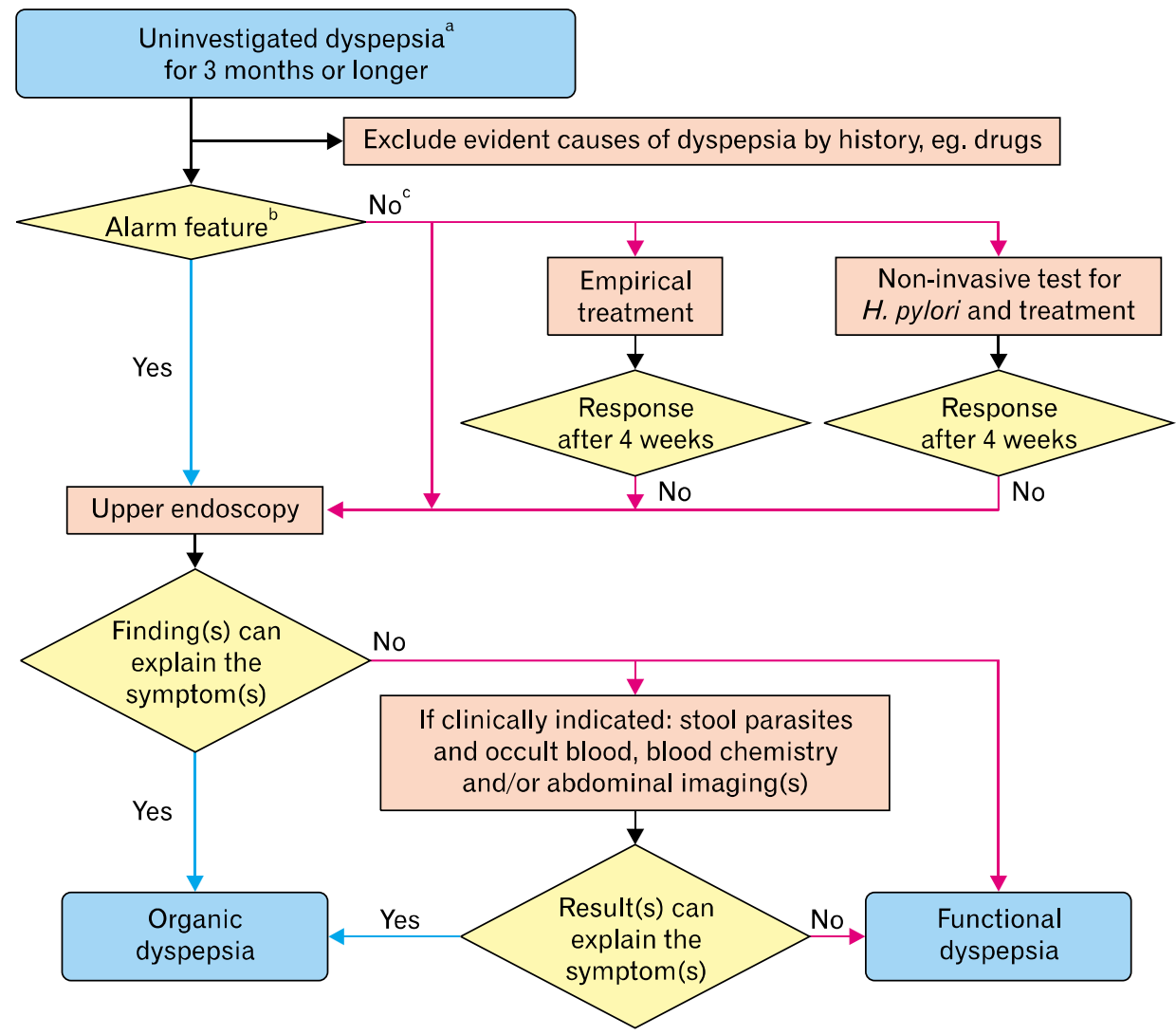

Figure 1. Diagnostic algorithm for functional dyspepsia in Asian primary care settings. ${ }^{a}$ Dyspepsia refers to a symptom or set of symptoms that are considered to originate from the gastroduodenal region. The dyspeptic symptoms are epigastric pain, epigastric burning, postprandial fullness, early satiation and other symptoms including bloating in the upper abdomen, nausea, vomiting and belching. Chronic dyspeptic symptoms can be continuous, intermittent or recurrent. More than two thirds of the consensus members agreed that symptom duration of 3 months or longer might be enough. ${ }^{b}$ The alarm features are unintended weight loss, progressive dysphagia, recurrent or persistent vomiting, evidence of gastrointestinal bleeding, anemia, fever, family history of gastric cancer, new onset dyspepsia in the subjects over 40 years of age in population with high prevalence of upper gastrointestinal malignancy and over 45 and 50 years in populations with intermediate and low prevalence, respectively. 'The appropriate choice from the three options depends on patient's symptom profiles, patient's wish, local risk of Helicobacter pylori infection and gastric cancer as well as local health care or re-imbursement system. H. pylori, Helicobacter pylori.

symptom duration of 6 months or longer was considered too long to make a diagnosis of FD in Asia. A study in Japan suggested that most patients with dyspeptic symptoms present to their doctors within 6 months after the first appearance of their symptoms. ${ }^{7}$ Twenty-six percent of the consensus members felt that in clinical practice a symptom duration of one month is enough to consider dyspeptic symptoms as being chronic, whereas $68 \%$ agreed with a duration of 3 months and only $5 \%$ agreed with the 6-month period as in the Rome III criteria (Fig. 1). However, most of the consensus members agreed that for research purposes, diagnosis of FD in Asia could follow the Rome III diagnostic criteria for FD.

Many organic, systemic or metabolic conditions such as peptic ulcer diseases, cancers of the GI and hepatobiliary tract, ${ }^{9,10}$ parasitic infestations, ${ }^{11-14}$ chronic pancreatic diseases, ${ }^{15}$ hyperand hypothyroidisms, ${ }^{16}$ chronic renal failures, ${ }^{17}$ and electrolyte imbalances, as well as medications, can produce symptoms similar to FD and should be considered before making a diagnosis of FD.

Statement 3. Diagnosis of functional dyspepsia and functional dyspepsia subgroups based on the Rome III criteria needs validation in Asia.

Grade of evidence: low.

Level of agreement: a: $100 \%$; b: $0 \%$; c: $0 \%$; d: $0 \%$; e: $0 \%$; f: $0 \%$.

All consensus members agreed with this statement. Since Asian countries have large differences in culture and language, the interpretation of GI symptoms is likely to be different from country to country. Unfortunately, there are no cross-ethnic or 


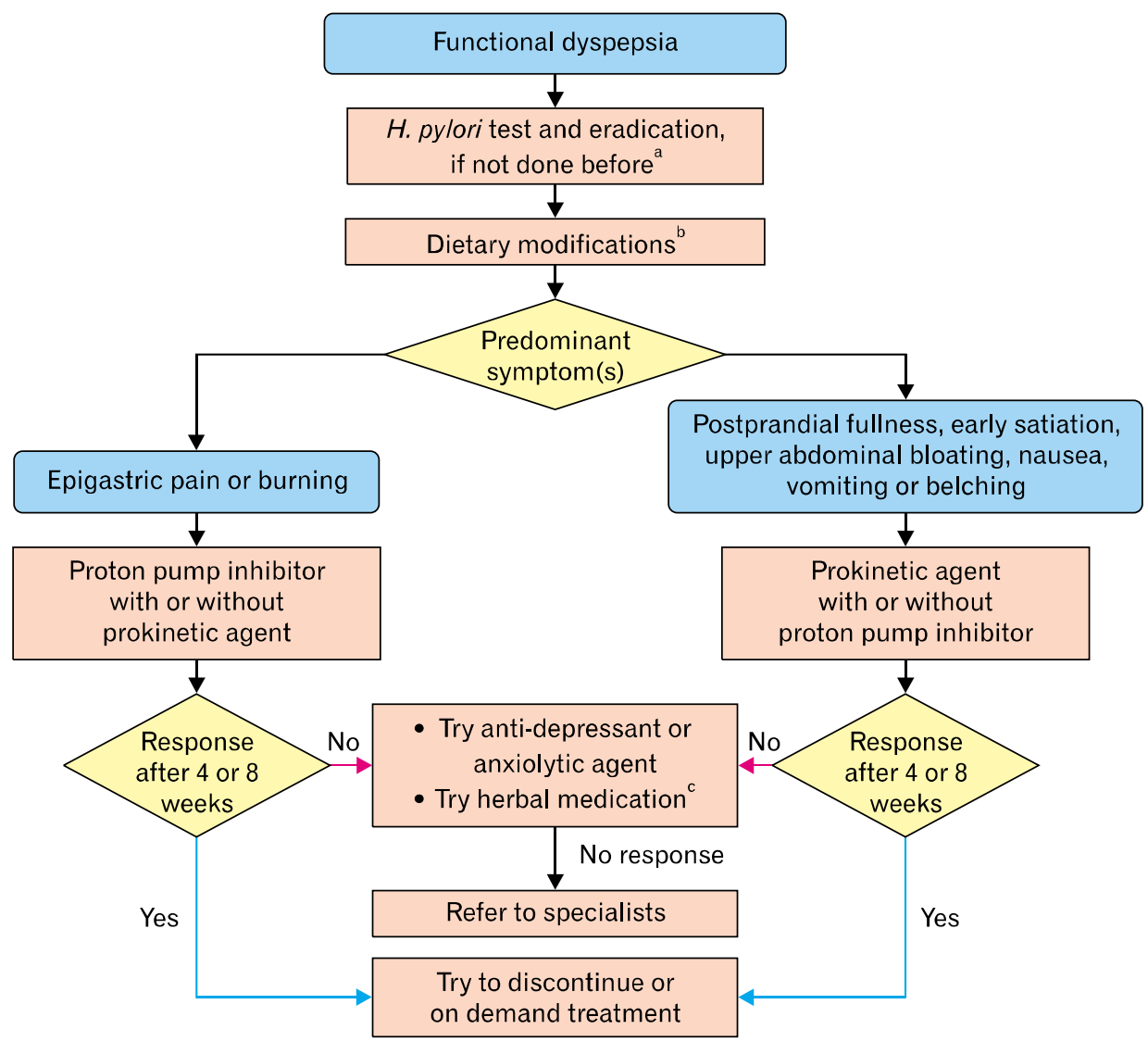

Figure 2. Management algorithm for functional dyspepsia in Asian primary care settings. ${ }^{a}$ Where socio-economic conditions allow, Helicobacter pylori test and eradication should be part of the management strategy for all patients presenting with dyspepsia in Asia. ${ }^{\mathrm{b}}$ Specific food ingredients may provoke dyspeptic symptoms. Dietary modification can be considered in functional dyspepsia but data are lacking. ${ }^{c}$ Where there is any available herbal medication previously validated, it may be tried. H. pylori, Helicobacter pylori.

cross-cultural studies to address this thesis currently.

\section{Statement 4. A diagnosis of functional dyspepsia can be considered on the basis of clinical symptoms and upper gastrointestinal endoscopy results (see Fig. 1).}

Grade of evidence: moderate.

Level of agreement: a: $78.9 \%$; b: $15.8 \%$; c: $5.3 \%$; d: $0 \%$; e: $0 \%$; f: $0 \%$.

Most of the consensus members agreed that for most patients with dyspeptic symptoms in Asia the clinical symptoms and upper GI endoscopic results are sufficient to consider a diagnosis of FD. However, several studies in Asia also included upper abdominal ultrasound as an important investigative tool for diagnosis of FD. ${ }^{18,19}$ Some patients with clinical features that cannot be explained by endoscopic findings may need further diagnostic investigations such as stool examination for parasites and occult blood, if clinically indicated (Fig. 1). For a diagnosis of FD, the upper GI endoscopic results should include no evidence of any diseases and conditions that can explain the dyspeptic symptoms. The presence of $H$. pylori infection in the absence of positive endoscopic findings does not exclude a diagnosis of FD presently.

Statement 5. Dyspepsia patients with alarm features should be investigated before the diagnosis of functional dyspepsia is accepted (see Fig. 1).

Grade of evidence: high.

Level of agreement: a: $94.7 \%$; b: $5.3 \%$; c: $0 \%$; d: $0 \%$; e: $0 \%$; f: $0 \%$.

Although several studies suggested that alarm features have a low positive predictive value for the diagnosis of organic causes in patients with dyspepsia, ${ }^{20}$ all of the consensus members agreed that if patients have any alarm features they should be investigated (Fig. 1). The alarm features are as follows: unintended weight loss; progressive dysphagia; recurrent or persistent vomiting; evidence of GI bleeding; anemia; fever; family history of gastric cancer; and new onset dyspepsia in a patient over 40 years 
of age in a population with high prevalence of upper GI malignancy, or over 45 or 50 years in a population with intermediate or low prevalence, respectively (see under Statement 8 for further discussion).

According to a recent review on the prevalence of gastric cancer in Asian countries, ${ }^{21}$ China, Korea and Japan are high-risk countries; Hong Kong, Malaysia, Singapore, Taiwan and Vietnam are intermediate-risk countries; and Bangladesh, India and Thailand are low-risk countries. It has been reported in Japan that most patients with early gastric cancer are asymptomatic and lack alarm features. ${ }^{10}$ Therefore, for early detection of gastric cancer in countries with high gastric cancer prevalence, doctors should follow their national gastric cancer screening guidelines instead of this dyspepsia consensus statement.

Statement 6. Other useful investigations for dyspepsia include complete blood cell count and blood biochemistry tests. Patients with dyspepsia should be tested for Helicobacter pylori infection. Stool examination for parasites in areas with high prevalence of infestations and fecal blood testing are also useful. Upper abdominal ultrasound or CT scan may be employed if indicated clinically (see Fig. 1).

Grade of evidence: moderate.

Level of agreement: a: $52.6 \%$; b: $36.8 \%$; c: $10.5 \%$; d: $0 \%$; e: $0 \%$; f: $0 \%$.

Most consensus members agreed that, if clinically indicated, complete blood count and blood biochemistry tests including tests for creatinine, ${ }^{17}$ electrolytes, sugar, thyroid function ${ }^{16}$ and liver function are useful for identifying underlying causes that may produce dyspeptic symptoms (Fig. 1). Although $H$. pylori testing is not used for diagnosis of FD, it is useful for the management of FD patients. Role of $H$. pylori is discussed under Statement 18. In areas with high prevalence of parasitic infestations, a stool examination for parasites is useful for identification of parasitic infestations such as ascariasis, ${ }^{14}$ fascioliasis, ${ }^{11}$ giardia lamblia ${ }^{12}$ and opisthorchiasis ${ }^{13}$ that can cause dyspeptic symptoms. Upper abdominal ultrasound or CT scan can be employed if clinically indicated, especially in areas with high prevalence of liver cancers that can present with dyspeptic symptoms. ${ }^{10}$

Statement 7. Gastric sensorimotor function tests including gastric emptying or accommodation studies may be useful in some subgroups of patients but are not recommended as routine clinical tests.

Grade of evidence: high.

Level of agreement: a: $84.2 \%$; b: $10.5 \%$; c: $5.3 \%$; d: $0 \%$; e:
0\%; f: $0 \%$.

Gastric function tests including gastric emptying test, electrogastrography, water load test, gastric accommodation test and gastric sensation test play controversial roles in the diagnosis and management of FD. ${ }^{22}$ These tests are poorly associated with dyspeptic symptoms and cannot predict a response to medical therapy in FD. Therefore, these tests should be reserved only for clinical research studies and evaluation in some specific subgroups of dyspeptic patients, such as patients with diabetic gastroparesis or generalized GI motility disorders.

\section{Epidemiology}

Statement 8. In Asian populations, the majority of patients with uninvestigated dyspepsia without alarm features have functional dyspepsia.

Grade of evidence: moderate.

Level of agreement: a: $68.4 \%$; b: $21.1 \%$; c: $10.5 \%$; d: $0 \%$; e: $0 \%$; f: $0 \%$.

In most studies from Asia, FD was diagnosed in most patients with uninvestigated dyspepsia (UD) after upper GI endoscopy. ${ }^{23}$ In a Chinese study of 782 patients with UD, 69\% turned out to have FD and the remaining $31 \%$ had organic causes. ${ }^{24}$ In a multi-center Asian study of 1,115 patients with UD (Rome II criteria) from 9 countries (China, Hong Kong, Indonesia, Korea, Malaysia, Singapore, Taiwan, Thailand and Vietnam), $43 \%$ turned out to have FD after investigations. ${ }^{25}$ In a Korean study of 476 patients with uninvestigated GI symptoms, $70 \%$ had functional GI disorders according to the Rome II criteria and $37 \%$ had FD. ${ }^{26}$ In a Malaysian study of 210 young patients with UD, $62 \%$ were diagnosed with FD. ${ }^{27}$ In a Singaporean study, 988 of 5,066 patients with UD had organic causes and the remaining $79.5 \%$ had $\mathrm{FD}{ }^{28}$

The cut-off age for considering a feature to be an alarm feature may vary in different populations based on the local epidemiological pattern of gastric cancer. In a Japanese study that considered 50 years as the cut-off age, frequency of FD was found to be lower among persons older than 50 years. ${ }^{29}$ In another study from Japan, of 1,730 gastric cancer patients, 27 were less than 34 years old. ${ }^{30}$ A study from India showed that patients with gastric cancer were older than patients with non-ulcer dyspepsia $\left(53 \pm 12\right.$ years vs $43 \pm 13$ years). ${ }^{31}$ These data might suggest that the cut-off age for considering endoscopic examination may vary by geographical area, though most believe that it should be 45 years of age. 


\section{Statement 9. A portion of Asian patients with functional dyspepsia has overlapping irritable bowel syndrome. \\ Grade of evidence: moderate. \\ Level of agreement: a: $100.0 \%$; b: $0 \%$; c: $0 \%$; d: $0 \%$; e: $0 \%$; f: $0 \%$.}

In Asian patients, there is a significant overlap between FD and IBS. In a Chinese study using the Rome III criteria, $24.8 \%$ of FD patients had overlapping IBS. ${ }^{8}$ In a study from India, dyspepsia-IBS overlap (dyspepsia was defined as abdominal pain or discomfort centered in the upper abdomen and IBS by Manning's criteria) was found in $14.2 \%$ of the FD subjects. ${ }^{32}$ Another Indian multi-center study demonstrated a high frequency (90\%) of upper abdominal pain or discomfort in IBS patients, although the diagnosis in that study was based on the clinicians' assessment rather than on the Rome criteria. ${ }^{33}$ In a Japanese study, the overlap of FD and IBS was found to be $3.5 \%$ of the patients with FD. ${ }^{34}$ In a study from Hong Kong using the Rome I criteria, overlapping IBS was found to be $16.9 \%$ of the subjects with dyspepsia. ${ }^{35}$ In a Japanese study using the Rome II criteria for the diagnosis of functional GI disorders, 181 medical students were recruited, and the overlap of IBS was found to be $66.7 \%$ of UD subjects. ${ }^{36}$ In a Korean study of 476 patients with functional GI disorders according to the Rome II criteria, the overlap of IBS was found in $20.8 \%$ of FD patients. ${ }^{26}$ In these studies, overlap of FD and IBS showed wide variation that might be due to diagnostic criteria, study populations, sociocultural issues, or symptom reporting by the patients.

\section{Statement 10. Patients with functional dyspepsia may have overlap with gastroesophageal reflux disease.}

Grade of evidence: moderate.

Level of agreement: a: $84.2 \%$; b: $15.8 \%$; c: $0 \%$; d: $0 \%$; e: $0 \%$; f: $0 \%$.

Overlap of FD and gastroesophageal reflux disease (GERD) is common in different Asian populations. ${ }^{23}$ A study from Turkey showed overlap of GERD to be $29.4 \%$ of subjects with symptoms of dyspepsia, ${ }^{37}$ and a study from Korea showed such overlap to be $24.1 \%$ of FD subjects. ${ }^{38}$ In both of those studies, GERD was diagnosed by questionnaire and not by 24-hour pH-impedance monitoring, which is currently the gold standard for diagnosis of GERD. Heartburn, which is the major symptom of GERD, may be influenced by the type of reporting by the patients because of sociocultural issues and lack of appropriate terminology in some Asian languages. ${ }^{39}$

\section{Statement 11. Quality of life is impaired in patients with functional dyspepsia.}

Grade of evidence: moderate.

Level of agreement: a: $84.2 \%$; b: $15.8 \%$; c: $0 \%$; d: $0 \%$; e: $0 \%$; f: $0 \%$.

Quality of life (QOL) is not good in patients with FD although it is not a fatal disease. The impairment of QOL in FD patients may be associated with significant burden on society due to work absenteeism, reduced productivity, and use of health care resources. $^{40,41}$ Data on QOL of patients with FD from Asia are scanty. However, in a Korean study of 1,417 subjects, the frequency of dyspepsia was found to be $11.7 \%$ according to the Rome III criteria. The Korean version of SF-36 was used to evaluate health-related QOL, and in patients with dyspepsia, the scores were worse for all 8 domains. ${ }^{42,43}$ Two studies from Malaysia by the same working team, one on a rural population and other on an urban population, showed using the EuroQOL (EQ-5D) instrument that subjects with dyspepsia (Rome II and III criteria) had lower health-related QOL. ${ }^{44-46}$

Statement 12. Psychological co-morbidity and socioeconomic factors may determine consultation behavior among patients with functional dyspepsia.

Grade of evidence: moderate.

Level of agreement: a: $100.0 \%$; b: $0 \%$; c: $0 \%$; d: $0 \%$; e: $0 \%$; f: $0 \%$.

Psychological illness is often associated with FD. In a Chinese study, psychological co-morbidity was assessed by the Hamilton Rating Scale for Depression (HRSD) and the Hamilton Anxiety Scale (HAS) in patients with FD and in healthy subjects before and after treatment for this disease. ${ }^{47}$ The data revealed a significant difference in HRSD and HAS scores between the FD patients and healthy subjects. Also, treatment with anti-depressant for 8 weeks resulted in improvement in scores. In a prospective, cross-sectional Malaysian study of 839 patients with dyspepsia, there were 472 patients with FD and 367 patients with organic causes. ${ }^{48}$ This study showed that anxiety was associated with both groups and that health-related QOL was lower in the patients with FD than in the patients with organic dyspepsia. Psychological factors associated with FD may influence consultation behavior in patients with FD. A populationbased study from Hong Kong revealed that anxiety was associated with medical consultation and sick leave among patients with dyspepsia. ${ }^{35}$ The study showed that the degree of anxiety was an independent factor associated with health care-seeking behavior in dyspeptic patients. However, bloating and incomplete 
evacuation were found to be more important determinants of consultation behavior than psychological factors in a recent review of the epidemiology of IBS, which is another common functional bowel disease that may have overlapping dyspeptic symptoms. ${ }^{49}$ More studies on this issue are needed.

\section{Pathophysiology}

\section{Statement 13. Pathogenesis of functional dyspepsia is} multifactorial.

Grade of evidence: high.

Level of agreement: a: $100.0 \%$; b: $0 \%$; c: $0 \%$; d: $0 \%$; e: $0 \%$; f: $0 \%$.

Many pathogenic factors have been proposed for FD, including motility abnormalities such as delayed gastric emptying, impaired gastric accommodation and hypersensitivity to gastric distension; psychological factors; excessive gastric acid secretion; H. pylori infection; genetic factors; environment in childhood and/or adolescence; diet; lifestyle; and prior GI infection. ${ }^{50-52}$ The major mechanism thought to induce FD symptoms includes impaired accommodation, delayed gastric emptying, and visceral hypersensitivity, as well as other complicating factors. ${ }^{51,53}$ Pharmacological correction of abnormal gastric motility and visceral hypersensitivity has been considered as a valid therapeutic approach in FD; however, changes in motor function and symptomatic outcomes are poorly correlated. ${ }^{54}$

Current evidence suggests that FD is a heterogeneous disorder in which different pathophysiological disturbances are associated with different symptom profiles. Progress in understanding the underlying pathogenetic mechanisms should lead to better targeting of treatment in FD patients. ${ }^{50}$

Statement 14. Disturbed gastroduodenal motility is one of the pathophysiologic mechanisms in functional dyspepsia.

Grade of evidence: high.

Level of agreement: a: $100.0 \%$; b: $0 \%$; c: $0 \%$; d: $0 \%$; e: $0 \%$; f: $0 \%$.

Disturbed gastroduodenal motility is considered to be one of the major pathophysiologic mechanisms in FD. ${ }^{4,51}$ Abnormal gastric motility has been analyzed from different aspects by various measures, and differences in findings between health and diseases have been characterized.

We intuitively recognize that delayed gastric emptying may be related to dyspeptic symptoms, especially feelings of retention of ingested food after meal, which can be abdominal distension, bloating or fullness. There are many reports demonstrating de- layed gastric emptying in patients with FD from both Wes$\operatorname{tern}^{55,56}$ and Asian ${ }^{57-63}$ countries, and about $40 \%$ of FD patients are thought to show delayed gastric emptying after ingestion of solid food. ${ }^{64}$ However, there are many studies that failed to show a direct connection between delayed gastric emptying and dyspeptic symptoms, ${ }^{65-67}$ suggesting that the relationship may not be entirely clear.

On the other hand, much attention has recently been paid to impaired gastric accommodation, which is also known as adaptive relaxation. The accommodation reflex is a volume response of the upper part of the stomach after a meal. After ingestion of food, the gastric fundus spontaneously dilates and begins to store food. Such impairment of gastric accommodation is known to correlate well with dyspeptic symptoms, especially early satiety. ${ }^{68,69}$ However, this relationship has not been confirmed well in studies from some Asian countries. ${ }^{70,71}$

Statement 15. Visceral hypersensitivity is one of the pathophysiologic mechanisms in functional dyspepsia.

Grade of evidence: high.

Level of agreement: a: $100.0 \%$; b: $0 \%$; c: $0 \%$; d: $0 \%$; e: $0 \%$; f: $0 \%$.

Visceral hypersensitivity has been reported to play a key role in the pathophysiology of FD. Several studies have clearly demonstrated that, as a group, patients with FD have enhanced sensitivity to distension of the proximal stomach. ${ }^{71-73}$ Abnormal central nervous system processing of visceral stimuli can be involved in hypersensitivity to proximal gastric distention. Patients with FD, who have hypersensitivity to gastric distension, more often report pain due to hyperalgesia. ${ }^{74}$ Pain occurs in hypersensitive dyspeptic patients at distending pressures that induce non-painful sensations. In these patients, various luminal stimuli including chemical and mechanical stimuli can be perceived as unpleasant discomfort or pain. A study from the West reveals that hypersensitivity to gastric distention is found in $34 \%$ of patients with FD. ${ }^{73}$ A study from Korea showed that $37.5 \%$ of Korean patients with FD had hypersensitivity to gastric distension. ${ }^{71}$ Although there is a report showing the association of this mechanism with symptoms of postprandial epigastric pain, belching and weight loss, ${ }^{73}$ this association has not been clearly established yet, particularly in Asia. ${ }^{71}$

Hypersensitivity to endogenous and exogenous chemicals, gastric acid or nutrients has been suggested to be associated with dyspeptic symptoms. ${ }^{75-77}$ Since patients with visceral hypersensitivity are considered to have enhanced sensory nerve activity, stimulation of luminal chemoreceptors in the upper GI mucosa 
may generate or aggravate dyspeptic symptoms. However, data on the prevalence and pathogenetic role of hypersensitivity to chemicals and nutrients in Asian patients with FD are lacking.

Statement 16. Psychosocial factors may play a role in functional dyspepsia.

Grade of evidence: moderate.

Level of agreement: a: $84.2 \%$; b: $15.8 \%$; c: $0 \%$; d: $0 \%$; e: $0 \%$; f: $0 \%$.

Psychological disturbances have been proposed as one of the possible causes of FD. ${ }^{48}$ Several population-based studies demonstrated that patients with FD have higher prevalence of depression and anxiety compared to control population and even patients with organic dyspepsia. ${ }^{48,78-80}$ It was shown that there is a gradual transition from mild to severe psychosocial morbidity parallel with dyspepsia symptom severity, ${ }^{78,81}$ and $\mathrm{Hsu}$ et $\mathrm{al}^{82}$ found that patients fulfilling the criteria for either postprandial distress syndrome or epigastric pain syndrome had psychologically more severe symptoms. In clinical practice, anti-anxiety or anti-depressive agents are sometimes prescribed for symptoms of FD. On the basis of a systematic review of the literature, Hojo et $\mathrm{al}^{83}$ concluded that anti-anxiety and anti-depressive agents may be effective treatments for FD.

Stressful life events in the patient's social environment are also thought to be associated with the onset or exacerbation of dyspeptic symptoms, although the relationship is still not clear. Some studies have shown that the number of stressful life events experienced by FD patients was more than that experienced by healthy controls, ${ }^{79,84,85}$ whereas others have found no significant difference in the number of such events. ${ }^{84,86}$ Hui et al ${ }^{86}$ indicated that differences in FD symptoms correlated with psychological factors such as negative perception of major life events rather than with the number of stressful life events experienced. Chen et $\mathrm{al}^{87}$ demonstrated that severity of stressful life events was positively correlated with disturbance of gastric myoelectric activity in FD patients. Coping pattern is a psychological factor associated with FD symptoms. ${ }^{84,86,88}$ Several psychological studies have found that effective coping strategies play a role in mitigating anxiety, depression and somatic problems. ${ }^{88,89}$ Cheng et al ${ }^{89}$ designed flexible coping psychotherapy for enhancing coping flexibility of FD patients and demonstrated that the psychotherapy significantly changed FD symptom severity. Lastly, familial factors may include psychological, environmental or genetic factors, which may contribute to abdominal symptoms of FD patients. Ahn et $\mathrm{al}^{90}$ found that family function score was lower in an FD group than in a normal control group, and Ochi et $\mathrm{al}^{91}$ suggested that parental criticism experienced in early life may underlie the psychological background of FD patients and correlated with their abdominal symptoms. All these results add support to the theory of psychosocial disturbances in the pathogenesis of FD.

Statement 17. Gastric acid may be responsible for the symptoms in a subset of patients with functional dyspepsia.

Grade of evidence: moderate.

Level of agreement: a: $89.5 \%$; b: $10.5 \%$; c: $0 \%$; d: $0 \%$; e: 0\%; f: $0 \%$.

Because anti-secretory therapy is effective in some patients with $\mathrm{FD},{ }^{92,93}$ it is thought that gastric acid may play a role in the pathogenesis of FD. However, it has not been clearly demonstrated that excessive gastric acid is a pathogenetic factor in FD, and data on the amount of gastric acid secretion in patients with FD are lacking. Results of studies from Asian countries are controversial. $^{94-96}$

Proton pump inhibitors (PPIs) are believed to be beneficial in a subset of patients with FD. This positive response is mainly confined to patients with ulcer-like and reflux-like dyspepsia. ${ }^{92}$ Patients with postprandial pain are reported to have a high prevalence of pathological acid exposure, which suggests that patients who respond to acid-suppressive therapy might have non-erosive reflux disease. ${ }^{97}$ Several studies have suggested a role for increased duodenal acid exposure or duodenal or gastric hypersensitivity to acid in the pathogenesis of symptoms in some patients with FD. ${ }^{76,98-100}$ These factors might explain the beneficial effects of acid-suppressive treatment for FD. However, the prevalence and pathogenetic role of these abnormalities in Asian patients with FD remains to be further explored.

\section{Statement 18. Helicobacter pylori may play a role in pathogenesis of functional dyspepsia.}

Grade of evidence: moderate.

Level of agreement: a: $52.6 \%$; b: $31.6 \%$; c: $5.3 \%$; d: $10.5 \%$; e: $0 \%$; f: $0 \%$.

The reported prevalence of $H$. pylori infection in patients with FD varies from $39 \%$ to $87 \% .^{101}$ Several epidemiological studies have shown that $H$. pylori infection occurs more frequently in FD than in matched control populations. A meta-analysis published in 1999 reported a summary odds ratio for $H$. pylori infection in FD of 1.6 (95\% CI, 1.4-1.8). ${ }^{102}$ Mechanistic studies found that H. pylori-infected FD patients had higher stimulated gastric acid output than $H$. pylori-negative healthy volunteers. ${ }^{103}$ However, no associations between $H$. pylori positivity and symptom pattern, gastric emptying rate, gastric accommodation or sensitivity to dis- 
tension in FD patients have been found. ${ }^{104}$

The effect of $H$. pylori eradication on dyspeptic symptoms in FD patients has been evaluated in several large, well-designed, randomized controlled trials, but the results were conflicting. ${ }^{105,106}$ Conflicting data have also been reported from Asia. ${ }^{29,107}$ Wong et al ${ }^{108}$ found that the standard treatment for $H$. pylori infection is suboptimal in FD compared with duodenal ulcer. A Cochrane systematic review showed that there was a $10 \%$ relative risk reduction in the $H$. pylori eradication group compared to placebo, and that the number needed to treat to cure one case of dyspepsia was $14 .{ }^{109}$ However, a recently published systematic review and meta-analysis from the Chinese literature found that the summary odds ratio for improvement in dyspeptic symptoms in patients with $\mathrm{FD}$ after $H$. pylori eradication was 3.61, suggesting that the role of this infection is much larger in the Chinese population than in Western populations. ${ }^{110}$

Some of the consensus members proposed that dyspepsia accompanied by $H$. pylori infection should be regarded as a different disease entity from FD. In other words, FD patients should be $H$. pylori-negative and $H$. pylori infection should be eradicated before making a diagnosis of FD. The logic behind this opinion was (1) histological gastritis is no longer a non-organic disease as it can be visually recognized by advanced endoscopic technologies, such as magnifying or narrow band imaging endoscopy; (2) H. pylori eradication is strongly recommended regardless of the presence of dyspeptic symptoms, especially in some Asian countries where gastric cancer is highly prevalent; and (3) the concept of post-infectious FD has already been recognized and H. pylori infection is apparently an infection that causes mucosal inflammation.

\section{Statement 19. Post-infectious functional dyspepsia occurs in a subset of patients.}

Grade of evidence: moderate.

Level of agreement: a: $73.7 \%$; b: $26.3 \%$; c: $0 \%$; d: $0 \%$; e: $0 \%$; f: $0 \%$.

FD has been reported to occur in patients following GI infection. In a prospective study from Spain, $14 \%$ of persons who were infected by shigella developed post-infectious dyspepsia, resulting in a relative risk of 5.2 compared to controls. ${ }^{111}$ Furthermore, a number of reports from Europe and Asia have shown that low-grade inflammation is found in the duodenum of patients with post-infectious FD. ${ }^{12,113}$ In a large retrospective tertiary center study, Tack et al ${ }^{114}$ showed that a subset of presumed post-infectious dyspepsia patients had higher prevalence of impaired accommodation of the proximal stomach. There is evi- dence that post-infectious FD can occur in a subset of patients, and functional abnormalities and persistent inflammation of the gut are found.

\section{Statement 20. Genetic factors may be involved in pathogenesis in a subset of patients with functional} dyspepsia.

Grade of evidence: low.

Level of agreement: a: $78.9 \%$; b: $15.8 \%$; c: $5.3 \%$; d: $0 \%$; e: $0 \%$; f: $0 \%$.

The G-protein $\beta 3$ subunit C825T polymorphism was reported to be associated with dyspepsia in studies from the United States (both CC and TT genotypes with meal-unrelated dyspepsia) ${ }^{115}$ and Germany (CC genotype). ${ }^{116}$ In contrast, the 825 -T allele was suggested to be related to dyspepsia in reports from Japan and the Netherlands. ${ }^{117-119}$ In Japanese groups, the following polymorphisms have been reported to be associated with the development of FD or dyspeptic symptoms: IL-17F 7488T, macrophage migration inhibitory factor $\mathrm{G}-173 \mathrm{C},{ }^{120}$ catechol-omethyltransferase gene val158met, ${ }^{121}$ T779C of cholecystokinin-1 intron $1,{ }^{122}$ cyclooxygenase-1 T-1676C, ${ }^{123}$ p22 phagocyte oxidase component of nicotinamide adenine dinucleotide phosphate oxidase $\mathrm{C}_{2} 42 \mathrm{~T}^{124}$ and transient receptor potential vanilloid 1 G315C. ${ }^{125}$ These data indicate that genetic factors are associated with the development of FD. However, the studies from Asia are limited and are only from Japan. Validation in other countries and in a large-scale study is warranted.

\section{Statement 21. Dietary factors and lifestyle may be involved in the pathogenesis of functional dyspepsia.}

Grade of evidence: low.

Level of agreement: a: $94.7 \%$; b: $5.3 \%$; c: $0 \%$; d: $0 \%$; e: $0 \%$; f: $0 \%$.

The investigation of lifestyle factors in FD has been limited to a few studies. From Asia, Chen et $\mathrm{al}^{79}$ and Mahadeva et $\mathrm{al}^{44}$ reported that tea drinking was negatively associated with FD. Theophylline in tea acts as a competitive antagonist to adenosine receptors, which induce epigastric pain and chest pain. ${ }^{126,127}$ However, there is little Asian literature on the types and amounts of tea drunk by dyspeptic patients.

More recently, the concept of visceral hypersensitivity to nutrient stimuli, especially hypersensitivity to fat, ${ }^{128,129}$ has been highlighted as an etiology of FD. ${ }^{130,131}$ Food ingestion is associated with stimulation of secretion of a range of GI hormones, including cholecystokinin and peptide YY, and suppression of ghrelin. ${ }^{132}$ It is conceivable that gut peptides play a role in the induction of dyspeptic symptoms in FD patients with nutrient 
hypersensitivity. In patients with FD, intolerance to specific foods is common and many foods are reported to induce symptoms. ${ }^{133}$ On the contrary, chili and rice ${ }^{134}$ and ginger ${ }^{135}$ are reported to be good for dyspepsia. Feinle-Bisset et $\mathrm{al}^{136}$ reported that postprandial fullness is the most severe symptom in patients reporting aggravation by meal.

Most studies concerning the relationships between lifestyle or dietary factors and FD are based on symptom intensities evaluated by questionnaire or on physiological studies involving particular foods or components. Further prospective studies are necessary to clarify the details of these pathogenetic factors and the role of dietary therapy in the management of FD.

\section{Management}

Statement 22. An integrated approach addressing physiological, biological, psychological and social factors is recommended for all patients with functional dyspepsia (see Fig. 2).

Grade of evidence: low.

Strength of recommendation: probably do it.

Level of agreement: a: $84.2 \%$; b: $10.5 \%$; c: $5.3 \%$; d: $0 \%$; e: $0 \%$; f: $0 \%$.

As the pathogenesis of FD is multi-factorial, treatment should be individualized, with an effort to identify as many possible putative factors as possible. There have been no direct data to support this approach to managing FD in general. On the other hand, there have been studies on IBS that demonstrate a favorable response to treatment when physicians make an effort to address possible contributing factors such as past GI infection (biological), psychosocial stressors (psychological) and dietary changes (social), to reassure the patient by providing reasonable evidence that he or she does not have a life-threatening condition, and to explain the diagnosis with appropriate pathophysiological (physiological) models. In view of the overlap in symptoms, patient demographics and putative pathophysiology, it is reasonable to recommend a similar approach to $\mathrm{FD}$, as was recommended in the recent Asian IBS Consensus. ${ }^{137-139}$

There is a study to support adopting a combination of intensive medical therapy with psychological intervention in patients with refractory FD. Haag et $\mathrm{al}^{140}{ }^{140}$ in prospective randomized, controlled trial, compared the long-term outcome of intensive medical therapy (with or without cognitive-behavioral or muscle relaxation therapy) versus standard medical therapy in patients with refractory FD and found that in FD patients with refractory symptoms, intensified medical management involving function testing and psychological intervention yielded superior long-term outcomes. There is also a study from China that showed psychological intervention to be superior to prokinetic therapy. ${ }^{141}$

Statement 23. Where socio-economic conditions allow, Helicobacter pylori testing and eradication should be part of the management strategy for all patients in Asia who present with dyspepsia (see Fig. 2).

Grade of evidence: high.

Strength of recommendation: do it.

Level of agreement: a: $58.0 \%$; b: $42.0 \%$; c: $0 \%$; d: $0 \%$; e: $0 \%$; f: $0 \%$.

H. pylori eradication has a statistically significant effect on symptom relief in patients with FD. Cochrane meta-analysis on 17 randomized controlled trials $(\mathrm{n}=3,566)$ found a small but statistically significant benefit of $H$. pylori eradication therapy at 12 months, with relative risk reduction of $10 \%$ (95\% CI, $6 \%-14 \%)$ and number needed to treat of 14 (95\% CI, 10-25). ${ }^{109}$ Studies from Asia included in this meta-analysis showed both positive $^{142,143}$ and negative ${ }^{107,144}$ results. However, in a recent meta-analysis of 7 Chinese studies, ${ }^{110}$ the summary odds ratio for symptom improvement by $H$. pylori eradication was 3.61 (95\% CI, 2.62-4.98; $P<0.0001)$, which was far higher than those of previously published meta-analyses. Recent studies from Singapore also support the role of $H$. pylori eradication in $\mathrm{FD},{ }^{145,146}$ suggesting that the benefit of $H$. pylori eradication therapy is possibly more significant in the Asian region. However, benefits of this strategy should be weighed against its costs including possible induction of high rate of antibiotic resistance in addition to the high financial burden in areas with high prevalence of $H$. pylori infection.

The recently published Asia Pacific consensus guidelines on H. pylori infection stated, " $H$. pylori eradication is indicated for H. pylori-positive patients with investigated dyspepsia (non-ulcer dyspepsia)." ${ }^{147}$ The basis for the recommendation, which was itemized by the guidelines, included the benefit of $H$. pylori eradication from the social aspect. In other words, eradication of $H$. pylori in patients with FD has the additional benefit of reducing the risks for peptic ulcer disease and gastric cancer.

In studies from South America and China, regions with high prevalence rates of $H$. pylori infection and high incidence rates of gastric cancer, $H$. pylori eradication produced significant increases in the rates of regression of intestinal metaplasia and gastric atrophy and lowered the risk of progression to intestinal metaplasia, ${ }^{148-153}$ providing evidence that $H$. pylori eradication has a 
direct impact on gastric cancer occurrence and reduces the risk of metachronous gastric cancer after endoscopic resection. A meta-analysis $^{154}$ of 6 randomized placebo-controlled $H$. pylori eradication trials $^{148,151,152,155-157}$ showed that with H. pylori eradication, the pooled relative risk of developing gastric cancer was 0.65 (95\% CI, 0.43-0.98).

Considering all these data, the management algorithm recommended to eradicate $H$. pylori if socioeconomic conditions allow (Fig. 2).

Statement 24. Proton pump inhibitors are effective for controlling symptoms in patients with functional dyspepsia, although supportive data from Asia are lacking (see Fig. 2).

Grade of evidence: moderate.

Strength of recommendation: do it.

Level of agreement: a: $75.0 \%$; b: $25.0 \%$; c: $0 \%$; d: $0 \%$; e: $0 \%$; f: $0 \%$.

The rationale for using PPIs in FD stems from both clinical as well as physiological perspectives. Studies showing overlap between non-erosive reflux disease (NERD) and FD also support use of PPI in patients with FD. ${ }^{158-161}$ Besides this, pathological esophageal acid exposure has been reported in Western FD patients without symptoms of heartburn. ${ }^{97,162}$

To date, 7 randomized controlled trials of PPI versus placebo have been reported. ${ }^{92,95,163-167}$ Six of the 7 studies were conducted in Western population and they demonstrated a benefit over placebo for symptom improvement in FD patients, ${ }^{92,163-167}$ though PPIs may not be effective in dysmotility-like dyspepsia. ${ }^{168}$ In fact, the combined effect of all 7 trials (2,387 PPI patients, 1,338 placebo patients) was expressed in a recent meta-analysis, ${ }^{169}$ which reported that there was a modest but statistically significant difference in symptom relief in patients receiving PPIs (40.3\%) compared with those given placebo (32.7\%), and the estimated number needed to treat was 14.6 patients $(95 \%$ CI, 8.7-57.1).

It must be noted that the only trial that showed negative results among the 7 trials in the above-mentioned meta-analysis was from Hong Kong. In addition, a recent randomized trial from Hong Kong that investigated the efficacy of a PPI on $H$. pylori-negative uninvestigated dyspeptic patients (epigastric pain and discomfort) also failed to show an efficacy of PPI over placebo. ${ }^{96}$ An open-labelled study from Singapore, also reported only a modest response to PPI. ${ }^{170}$ Characteristic differences between Asian and Western patients with FD may explain the lower benefit of PPIs in Asian patients. These data suggest that the efficacy of PPIs in patients with FD needs to be reevaluated in the Asian population.

Statement 25. High-dose proton pump inhibitor therapy is not superior to standard doses for symptom control in functional dyspepsia.

Grade of evidence: moderate.

Strength of recommendation: probably not do it.

Level of agreement: a: $65.0 \%$; b: $25.0 \%$; c: $10.0 \%$; d: $0 \%$; e: $0 \%$; f: $0 \%$.

Several studies have examined the role of standard and higher doses of PPI in the treatment of FD..$^{95,164-166,168}$ Whether the patients responded to PPIs or not, these studies, which involved a large number of patients, consistently found no difference in symptom response between standard and higher PPI doses. A recent meta-analysis also concluded that the dose of PPI did not influence the response of FD symptoms to treatment. ${ }^{169}$ It is therefore proposed that a standard dose of PPI is sufficient in the management of $\mathrm{FD}$, and that dose escalation is unlikely to further reduce symptoms.

Another concern regarding the use of higher doses of PPI in patients with FD relates to incurring unwanted problems caused by acid inhibition. Recent studies of healthy, asymptomatic volunteers who received PPI treatment for either 4 or 8 weeks demonstrated rebound acid hypersecretion following withdrawal of the PPI, resulting in the development of dyspeptic symptoms after PPI treatment. ${ }^{171,172}$ Yet another concern regarding PPI administration relates to the development of small intestinal bacterial overgrowth (SIBO) in patients receiving long-term therapy. ${ }^{173}$ Although long-term PPI therapy has not been advocated in $\mathrm{FD}$, the risk of SIBO may be greater in patients on higher PPI doses than in patients on standard PPI doses. ${ }^{173}$

Statement 26. Prokinetics may provide symptom relief in some functional dyspepsia patients (see Fig. 2).

Grade of evidence: moderate.

Strength of recommendation: do it.

Level of agreement: a: $90.0 \%$; b: $10.0 \%$; c: $0 \%$; d: $0 \%$; e: $0 \%$; f: $0 \%$.

Prokinetic agents, such as metoclopramide, domperidone, trimebutine, cisapride, itopride, mosapride, levosulpiride and cinitapride, can stimulate digestive tract motility via different mechanisms. Use of cisapride is currently restricted in most Asian countries because of its cardiovascular complications. Because delayed gastric emptying is considered a potential contributing factor to FD symptoms, prokinetic agents are often used in FD. In a meta-analysis from the Cochrane library that in- 
cluded 24 randomized controlled trials with 3,178 patients, the efficacy of prokinetics was superior to placebo ( $57 \%$ vs $47 \%){ }^{93}$ However, studies on prokinetics in FD had limitations due to the high degree of heterogenicity and small sample size. ${ }^{93,174}$

The clinical trial data for the new drug acotiamide showed a clear margin of symptom improvement compared with placebo, and may be approved for FD of the postprandial distress syndrome subtype. ${ }^{175,176}$

Statement 27. Some studies from Asia reported that herbal medications provide symptom relief in functional dyspepsia (see Fig. 2).

Grade of evidence: moderate.

Strength of recommendation: probably do it.

Level of agreement: a: $60.0 \%$; b: $40.0 \%$; c: $0 \%$; d: $0 \%$; e: $0 \%$; f: $0 \%$.

Limited studies have shown potential benefit of herbal medicines for symptom relief in FD patients. In a meta-analysis that included 33 studies on the efficacy of xiaoyao san (XS), ${ }^{177}$ a well-known traditional Chinese herbal formula for FD treatment, modified XS without (OR, 3.26; 95\% CI, 2.24-4.47) or with (OR, 4.32; 95\% CI, 2.64-7.08) prokinetics significantly reduced symptoms compared with prokinetics alone. However, the reporting of quality issues in these studies was generally poor. These studies are usually non-randomized, non-blinded and without placebo control. Therefore, high-quality controlled trials are required to assess the effects of XS in comparison to placebo. Another relatively small-scaled but placebo-controlled study from Japan demonstrated the efficacy of the Japanese herbal medicine rikkunshito (TJ-43) in reducing GI symptoms in FD patients and accelerating gastric emptying. ${ }^{178}$ This medicine was found to improve gastric accommodation in a study using extracorporeal ultrasonography. ${ }^{179}$

Statement 28. Anti-depressant and anxiolytic agents have a role in the management of functional dyspepsia, despite the limited evidence (see Fig. 2).

Grade of evidence: low.

Strength of recommendation: probably do it.

Level of agreement: a: $80.0 \%$; b: $20.0 \%$; c: $0 \%$; d: $0 \%$; e: 0\%; f: $0 \%$.

Evidence supporting the use of psychotherapy in treatment of FD is inconsistent and weak. ${ }^{180}$ As for pharmacological therapies, only limited studies of anti-depressants or anxiolytic drugs are available. In a small study involving only 7 FD patients with sleep disturbance, low-dose amitriptyline improved dyspeptic symptoms more than placebo did. ${ }^{181}$ In a series of studies from
Dublin, buspirone, a partial 5-hydroxytryptamine $1 \mathrm{~A}\left(5-\mathrm{HT}_{1 \mathrm{~A}}\right)$ agonist with anti-depressant and anxiolytic effects, was shown to improve dyspeptic symptoms in FD, with associated enhanced prolactin release in FD patients compared with controls, suggesting that central $\mathrm{HT}_{1 \mathrm{~A}}$ receptors may be supersensitive in $\mathrm{FD}$ patients. ${ }^{182-184}$ A recent study from Japan showed that symptom resolution was significantly greater in FD patients treated with tandospirone, a 5- $\mathrm{HT}_{1 \mathrm{~A}}$ agonist with anxiolytic activity, than in patients given a placebo. ${ }^{185}$ On the contrary, venlafaxine, a serotonin and norepinephrine reuptake inhibitor, failed to show positive results and a greater number of patients on venlafaxine than on placebo dropped out of the study because of side effects. ${ }^{186}$

Central factors, such as psychological disturbance, sleep disturbance and central serotonin receptor sensitivity, may be important determinants of response to anti-depressant treatment in FD patients. In an open-label study from Taiwan, fluoxetine improved GI symptoms in depressed but not in non-depressed FD patients, ${ }^{187}$ and in a study from Norway, high levels of neuroticism and concealed aggressiveness predicted poor response to mianserin, a tetracyclic anti-depressant. ${ }^{188}$

Statement 29. Specific food ingredients such as chili, spice and fats may provoke dyspeptic symptoms. Dietary modification can be considered in functional dyspepsia but data are lacking (see Fig. 2).

Grade of evidence: low.

Strength of recommendation: probably do it.

Level of agreement: a: $80.0 \%$; b: $20.0 \%$; c: $0 \%$; d: $0 \%$; e: $0 \%$; f: $0 \%$.

Although patients frequently believe that certain foods are the cause of their symptoms, there are few good studies to exclude the effect of psychological bias in the patient's perception. However, experimental studies suggest that certain food ingredients such as chili, spice and fats may provoke dyspeptic symptoms. Most importantly, there is no well-controlled study to demonstrate that dietary exclusion of specific food ingredients is effective for symptom control in FD. ${ }^{45,128,129,133,134,136,189-196}$

\section{Conclusion}

This consensus was developed to attract attention to the data from Asian countries, to articulate the experience and views of Asian experts, and to provide a relevant guide on management of FD for primary care physicians working in Asia. This consensus shows distinctive features of FD in Asia and will provide a guide to the diagnosis and management of $\mathrm{FD}$ for Asian primary care 
physicians. The understanding of FD is still incomplete and is evolving over time and this consensus report will be revised as our understanding of FD grows.

\section{Acknowledgements}

As a collaborative work of the Asian Neurogastroenterology and Motility Association (ANMA) and the Asian Pacific Association of Gastroenterology, this manuscript is published simultaneously, by agreement of the respective Editors-in-Chief, in the Journal of Neurogastroenterology and Motility and the Journal of Gastroenterology and Hepatology and may be referenced under either journal. This consensus process was not directly sponsored by any commercial companies. The first face-to-face meeting in Kuala Lumpur was sponsored by the Steering Committee of ANMA and the second face-to-face meeting in Beijing was sponsored by the Organizing Committee of ANMA 2011 Beijing Congress. No consensus team member has any financial disclosure to declare in relationship with this consensus process.

\section{References}

1. Colin-Jones D, Bloom B, Bodemar G, et al. Management of dyspepsia: report of a working party. Lancet 1988;331:576-579.

2. Murphy MK, Black NA, Lamping DL, et al. Consensus development methods, and their use in clinical guideline development. Health Technol Assess 1998;2:i-iv, 1-88.

3. Atkins D, Best D, Briss PA, et al. Grading quality of evidence and strength of recommendations. BMJ 2004;328:1490.

4. Tack J, Talley NJ, Camilleri M, et al. Functional gastroduodenal disorders. Gastroenterology 2006;130:1466-1479.

5. Tuteja AK, Talley NJ, Joos SK, Tolman KG, Hickam DH. Abdominal bloating in employed adults: prevalence, risk factors, and association with other bowel disorders. Am J Gastroenterol 2008; 103:1241-1248.

6. Jiang X, Locke GR3rd, Choung RS, Zinsmeister AR, Schleck CD, Talley NJ. Prevalence and risk factors for abdominal bloating and visible distention: a population-based study. Gut 2008;57:756-763.

7. Manabe N, Haruma K, Hata J, et al. Clinical characteristics of Japanese dyspeptic patients: is the Rome III classification applicable? Scand J Gastroenterol 2010;45:567-572.

8. Wang A, Liao X, Xiong L, et al. The clinical overlap between functional dyspepsia and irritable bowel syndrome based on Rome III criteria. BMC Gastroenterol 2008;8:43.

9. Suzuki H, Gotoda T, Sasako M, Saito D. Detection of early gastric cancer: misunderstanding the role of mass screening. Gastric Cancer 2006;9:315-319.

10. Ryu E, Kim K, Cho MS, Kwon IG, Kim HS, Fu MR. Symptom clusters and quality of life in Korean patients with hepatocellular carcinoma. Cancer Nurs 2010;33:3-10.

11. Karahocagil MK, Akdeniz H, Sunnetcioglu M, et al. A familial outbreak of fascioliasis in Eastern Anatolia: a report with review of literature. Acta Trop 2011;118:177-183.

12. Grazioli B, Matera G, Laratta C, et al. Giardia lamblia infection in patients with irritable bowel syndrome and dyspepsia: a prospective study. World J Gastroenterol 2006;12:1941-1944.

13. Upatham ES, Viyanant V, Kurathong S, et al. Relationship between prevalence and intensity of Opisthorchis viverrini infection, and clinical symptoms and signs in a rural community in north-east Thailand. Bull World Health Organ 1984;62:451-461.

14. Khuroo NS, Khuroo MS. Gastric ascariasis presenting as unique dyspeptic symptoms in an endemic area. Am J Gastroenterol 2010; 105:1675-1677.

15. Chen WX, Zhang WF, Li B, et al. Clinical manifestations of patients with chronic pancreatitis. Hepatobiliary Pancreat Dis Int 2006;5: 133-137.

16. Gunsar F, Yilmaz S, Bor S, et al. Effect of hypo- and hyperthyroidism on gastric myoelectrical activity. Dig Dis Sci 2003;48: 706-712.

17. Van Vlem B, Schoonjans R, Vanholder R, Vandamme W, De Vos M, Lameire N. Dyspepsia and gastric emptying in chronic renal failure patients. Clin Nephrol 2001;56:302-307.

18. Ashizawa N, Hashimoto T, Miyake T, Shizuku T, Imaoka T, Kinoshita Y. Efficacy of camostat mesilate compared with famotidine for treatment of functional dyspepsia: is camostat mesilate effective? J Gastroenterol Hepatol 2006;21:767-771.

19. Gonlachanvit S, Mahachai V, Chaiwatanarat T, Kullavanijaya $P$. Lack of effect of Helicobacter pylori on symptom improvement with a prokinetic medication, cisapride, in patients with non-ulcer dyspepsia. J Med Assoc Thai 2005;88:660-667.

20. Vakil N, Moayyedi P, Fennerty MB, Talley NJ. Limited value of alarm features in the diagnosis of upper gastrointestinal malignancy: systematic review and meta-analysis. Gastroenterology 2006;131: 390-401.

21. Fock KM, Ang TL. Epidemiology of Helicobacter pylori infection and gastric cancer in Asia. J Gastroenterol Hepatol 2010;25:479486.

22. Parkman HP, Jones MP. Tests of gastric neuromuscular function. Gastroenterology 2009;136:1526-1543.

23. Ghoshal UC, Singh R, Chang FY, Hou X, Wong BCY, Kachintorn U. Epidemiology of uninvestigated and functional dyspepsia in Asia: facts and fiction. J Neurogastroenterol Motil 2011;17:235-244.

24. Li XB, Liu WZ, Ge ZZ, et al. Analysis of clinical characteristics of dyspeptic symptoms in Shanghai patients. Chin J Dig Dis 2005;6: 62-67.

25. Kwan AC, Bao TN, Chakkaphak S, et al. Validation of Rome II criteria for functional gastrointestinal disorders by factor analysis of symptoms in Asian patient sample. J Gastroenterol Hepatol 2003;18: 796-802.

26. Kim JS, Lee KJ, Kim JH, Hahm KB, Cho SW. Functional gastrointestinal disorders in patients referred to specialist gastroenterologists in a tertiary hospital. Korean J Neurogastroenterol Motil 2004;10:111-117.

27. Mahadeva S, Chia YC, Vinothini A, Mohazmi M, Goh KL. Cost-effectiveness of and satisfaction with a Helicobacter pylori "test 
and treat" strategy compared with prompt endoscopy in young Asians with dyspepsia. Gut 2008;57:1214-1220.

28. Wai CT, Yeoh KG, Ho KY, Kang JY, Lim SG. Diagnostic yield of upper endoscopy in Asian patients presenting with dyspepsia. Gastrointest Endosc 2002;56:548-551.

29 Kawamura A, Adachi K, Takashima T, et al. Prevalence of functional dyspepsia and its relationship with Helicobacter pylori infection in a Japanese population. J Gastroenterol Hepatol 2001;16:384-388.

30. Nakamura R, Saikawa $Y$, Takahashi T, et al. Retrospective analysis of prognostic outcome of gastric cancer in young patients. Int $\mathrm{J}$ Clin Oncol 2011;16:328-334.

31. Ghoshal UC, Tiwari S, Dhingra S, et al. Frequency of Helicobacter pylori and CagA antibody in patients with gastric neoplasms and controls: the Indian enigma. Dig Dis Sci 2008;53:1215-1222.

32. Shah SS, Bhatia SJ, Mistry FP. Epidemiology of dyspepsia in the general population in Mumbai. Indian J Gastroenterol 2001;20: 103-106.

33. Ghoshal UC, Abraham P, Bhatt $\mathrm{C}$, et al. Epidemiological and clinical profile of irritable bowel syndrome in India: report of the Indian Society of Gastroenterology Task Force. Indian J Gastroenterol 2008;27:22-28.

34. Okumura T, Tanno S, Ohhira M, Tanno S. Prevalence of functional dyspepsia in an outpatient clinic with primary care physicians in Japan. J Gastroenterol 2010;45:187-194.

35. Hu WH, Wong WM, Lam CL, et al. Anxiety but not depression determines health care-seeking behaviour in Chinese patients with dyspepsia and irritable bowel syndrome: a population-based study. Aliment Pharmacol Ther 2002;16:2081-2088.

36. Hori K, Matsumoto T, Miwa H. Analysis of the gastrointestinal symptoms of uninvestigated dyspepsia and irritable bowel syndrome. Gut Liver 2009;3:192-196.

37. Kitapsioğlu G, Mandiracioğlu A, Caymaz Bor C, Bor S. Overlap of symptoms of dyspepsia and gastroesophageal reflux in the community. Turk J Gastroenterol 2007;18:14-19.

38. Lee SY, Lee KJ, Kim SJ, Cho SW. Prevalence and risk factors for overlaps between gastroesophageal reflux disease, dyspepsia, and irritable bowel syndrome: a population-based study. Digestion 2009;79: 196-201.

39. Sperber AD. The challenge of cross-cultural, multi-national research: potential benefits in the functional gastrointestinal disorders. Neurogastroenterol Motil 2009;21:351-360.

40. Lu CL, Lang HC, Chang FY, et al. Prevalence and health/social impacts of functional dyspepsia in Taiwan: a study based on the Rome criteria questionnaire survey assisted by endoscopic exclusion among a physical check-up population. Scand J Gastroenterol 2005;40: 402-411.

41. Moayyedi P, Mason J. Clinical and economic consequences of dyspepsia in the community. Gut 2002;50(suppl 4):iv10-iv12.

42. Jeong JJ, Choi MG, Cho YS, et al. Chronic gastrointestinal symptoms and quality of life in the Korean population. World J Gastroenterol 2008;14:6388-6394.

43. Hu WH, Lam KF, Wong YH, et al. The Hong Kong index of dyspepsia: a validated symptom severity questionnaire for patients with dyspepsia. J Gastroenterol Hepatol 2002;17:545-551.

44. Mahadeva S, Yadav H, Rampal S, Goh KL. Risk factors associated with dyspepsia in a rural Asian population and its impact on quality of life. Am J Gastroenterol 2010;105:904-912.

45. Mahadeva S, Yadav H, Rampal S, Everett SM, Goh KL. Ethnic variation, epidemiological factors and quality of life impairment associated with dyspepsia in urban Malaysia. Aliment Pharmacol Ther 2010;31:1141-1151.

46. Mahadeva S, Wee HL, Goh KL, Thumboo J. The EQ-5D (Euroqol) is a valid generic instrument for measuring quality of life in patients with dyspepsia. BMC Gastroenterol 2009;9:20.

47. Pan XP, Li YY, Sha WH, Yang FY. Psychological factors in functional dyspepsia and its treatment. Chin J Dig Dis 2000;1:17-20.

48. Mahadeva S, Goh KL. Anxiety, depression and quality of life differences between functional and organic dyspepsia. J Gastroenterol Hepatol 2011;26(suppl 3):49-52.

49. Gwee KA, Lu CL, Ghoshal UC. Epidemiology of irritable bowel syndrome in Asia: something old, something new, something borrowed. J Gastroenterol Hepatol 2009;24:1601-1607.

50. Lee KJ, Kindt S, Tack J. Pathophysiology of functional dyspepsia. Best Pract Res Clin Gastroenterol 2004;18:707-716.

51. Miwa H, Watari J, Fukui H, et al. Current understanding of pathogenesis of functional dyspepsia. J Gastroenterol Hepatol 2011; 26(suppl 3):53-60.

52. Mimidis K, Tack J. Pathogenesis of dyspepsia. Dig Dis 2008;26: 194-202.

53. Kato M, Nishida U, Nishida M, et al. Pathophysiological classification of functional dyspepsia using a novel drinking-ultrasonography test. Digestion 2010;82:162-166.

54. Tack J. Prokinetics and fundic relaxants in upper functional GI disorders. Curr Opin Pharmacol 2008;8:690-696.

55. Perri F, Clemente R, Festa V, et al. Patterns of symptoms in functional dyspepsia: role of Helicobacter pylori infection and delayed gastric emptying. Am J Gastroenterol 1998;93:2082-2088.

56. Sarnelli G, Caenepeel P, Geypens B, Janssens J, Tack J. Symptoms associated with impaired gastric emptying of solids and liquids in functional dyspepsia. Am J Gastroenterol 2003;98:783-788.

57. Rahim MK, Durr-e-Sabih, Mateen A, Najam-Uddin, Yousaf M. Studies of gastric emptying time in patients with non-ulcer dyspepsia. Nucl Med Commun 2007;28:852-858.

58. Aoki S, Haruma K, Kusunoki H, et al. Evaluation of gastric emptying measured with the 13C-octanoic acid breath test in patients with functional dyspepsia: comparison with ultrasonography. Scand J Gastroenterol 2002;37:662-666.

59. Duan LP, Zheng ZT, Li YN. A study of gastric emptying in non-ulcer dyspepsia using a new ultrasonographic method. Scand J Gastroenterol 1993;28:355-360.

60. Shindo T, Futagami S, Hiratsuka T, et al. Comparison of gastric emptying and plasma ghrelin levels in patients with functional dyspepsia and non-erosive reflux disease. Digestion 2009;79:65-72.

61. Takamori K, Mizuta Y, Takeshima F, et al. Relation among plasma ghrelin level, gastric emptying, and psychologic condition in patients with functional dyspepsia. J Clin Gastroenterol 2007;41:477-483.

62. Chang CS, Chen GH, Kao CH, Wang SJ, Peng SN, Huang CK. The effect of Helicobacter pylori infection on gastric emptying of digestible and indigestible solids in patients with nonulcer dyspepsia. Am J Gastroenterol 1996;91:474-479.

63. Waldron B, Cullen PT, Kumar R, et al. Evidence for hypomotility in non-ulcer dyspepsia: a prospective multifactorial study. Gut 1991;32: 
246-251.

64. Quartero AO, de Wit NJ, Lodder AC, Numans ME, Smout AJ, Hoes AW. Disturbed solid-phase gastric emptying in functional dyspepsia: a meta-analysis. Dig Dis Sci 1998;43:2028-2033.

65. Tack J, Bisschops R, Sarnelli G. Pathophysiology and treatment of functional dyspepsia. Gastroenterology 2004;127:1239-1255.

66. Talley NJ, Verlinden M, Jones M. Can symptoms discriminate among those with delayed or normal gastric emptying in dysmotility-like dyspepsia? Am J Gastroenterol 2001;96:1422-1428.

67. Wegener M, Börsch G, Schaffstein J, Reuter C, Leverkus F. Frequency of idiopathic gastric stasis and intestinal transit disorders in essential dyspepsia. J Clin Gastroenterol 1989;11:163-168.

68. Tack J, Piessevaux H, Coulie B, Caenepeel P, Janssens J. Role of impaired gastric accommodation to a meal in functional dyspepsia. Gastroenterology 1998;115:1346-1352.

69. Piessevaux H, Tack J, Walrand S, Pauwels S, Geubel A. Intragastric distribution of a standardized meal in health and functional dyspepsia: correlation with specific symptoms. Neurogastroenterol Motil 2003;15:447-455.

70. Hou XH, Li Q, Zhu L, Xie X, Chen JD. Correlation of gastric liquid emptying with various thresholds of sensation in healthy controls and patients with functional dyspepsia. Dig Dis Sci 2004;49: 188-195.

71. Rhee PL, Kim YH, Son HJ, et al. The etiologic role of gastric hypersensitivity in functional dyspepsia in Korea. J Clin Gastroenterol 1999;29:332-335.

72. Mertz H, Fullerton S, Naliboff B, Mayer EA. Symptoms and visceral perception in severe functional and organic dyspepsia. Gut 1998;42:814-822.

73. Tack J, Caenepeel P, Fischler B, Piessevaux H, Janssens J. Symptoms associated with hypersensitivity to gastric distention in functional dyspepsia. Gastroenterology 2001;121:526-535.

74. Vandenberghe J, Vos R, Persoons P, Demyttenaere K, Janssens J, Tack J. Dyspeptic patients with visceral hypersensitivity: sensitisation of pain specific or multimodal pathways? Gut 2005;54:914-919.

75. Lee KJ, Tack J. Duodenal implications in the pathophysiology of functional dyspepsia. J Neurogastroenterol Motil 2010;16:251-257.

76. Son HJ, Rhee PL, Kim JJ, Koh KC, Paik SW, Rhee JC. Hypersensitivity to acid in ulcer-like functional dyspepsia. Korean J Intern Med 1997;12:188-192.

77. Hammer J, Fuhrer M, Pipal L, Matiasek J. Hypersensitivity for capsaicin in patients with functional dyspepsia. Neurogastroenterol Motil 2008;20:125-133.

78. Li Y, Nie Y, Sha W, Su H. The link between psychosocial factors and functional dyspepsia: an epidemiological study. Chin Med J 2002;115:1082-1084.

79. Chen TS, Luo JC, Chang FY. Psychosocial-spiritual factors in patients with functional dyspepsia: a comparative study with normal individuals having the same endoscopic features. Eur J Gastroenterol Hepatol 2010;22:75-80.

80. Kang SG, Kim HJ, Lee SY, Cha MJ, Hwang HH. A study of anger, alexithymia, and depression in the functional dyspepsia. J Korean Acad Fam Med 2002;23:881-889.

81. Mujakovic S, de Wit NJ, van Marrewijk CJ, et al. Psychopathology is associated with dyspeptic symptom severity in primary care patients with a new episode of dyspepsia. Aliment Pharmacol Ther 2009;
29:580-588.

82. Hsu YC, Liou JM, Liao SC, et al. Psychopathology and personality trait in subgroups of functional dyspepsia based on Rome III criteria. Am J Gastroenterol 2009;104:2534-2542.

83. Hojo M, Miwa H, Yokoyama T, et al. Treatment of functional dyspepsia with antianxiety or antidepressive agents: systematic review. J Gastroenterol 2005;40:1036-1042.

84. Lee S, Park M, Choi S, Nah Y, Abbey SE, Rodin G. Stress, coping, and depression in non-ulcer dyspepsia patients. J Psychosom Res 2000;49:93-99.

85. Moon JI, Go EH,Kim SY, Hwang IH. Comparison of stressful life events among peptic ulcer, not ulcer dyspepsia and control groups. J Korean Acad Fam Med 1999;20:804-811.

86. Hui WM, Shiu LP, Lam SK. The perception of life events and daily stress in nonulcer dyspepsia. Am J Gastroenterol 1991;86:292-296.

87. Chen TS, Lee YC, Chang FY, Wu HC, Lee SD. Psychosocial distress is associated with abnormal gastric myoelectrical activity in patients with functional dyspepsia. Scand J Gastroenterol 2006;41: 791-796.

88. Cheng C, Hui WM, Lam SK. Coping style of individuals with functional dyspepsia. Psychosom Med 1999;61:789-795.

89. Cheng C, Yang FC, Jun S, Hutton JM. Flexible coping psychotherapy for functional dyspeptic patients: a randomized, controlled trial. Psychosom Med 2007;69:81-88.

90. Ahn MK, Lee SY, Kim YJ. The relationship between functional dyspepsia and family function. J Korean Acad Fam Med 1999;20: 917-924.

91. Ochi M, Tominaga K, Iketani T, et al. Perfectionism underlying psychological background correlated with the symptoms of functional dyspepsia. J Gastroenterol 2008;43:699-704.

92. Talley NJ, Meineche-Schmidt V, Paré P, et al. Efficacy of omeprazole in functional dyspepsia: double-blind, randomized, placebo-controlled trials (the Bond and Opera studies). Aliment Pharmacol Ther 1998;12:1055-1065.

93. Moayyedi P, Soo S, Deeks J, Delaney B, Innes M, Forman D. Pharmacological interventions for non-ulcer dyspepsia. Cochrane Database Syst Rev 2006;(4):CD001960.

94. Seno H, Nakase H, Chiba T. Usefulness of famotidine in functional dyspepsia patient treatment: comparison among prokinetic, acid suppression and antianxiety therapies. Aliment Pharmacol Ther 2005;21(suppl 2):32-36.

95. Wong WM, Wong BC, Hung WK, et al. Double blind, randomised, placebo controlled study of four weeks of lansoprazole for the treatment of functional dyspepsia in Chinese patients. Gut 2002;51: 502-506.

96. Leung WK, Wu JC, Chan FK, et al. Initial treatment with lansoprazole in young dyspeptic patients with negative urea breath test result: a randomized controlled trial with 12-month follow-up. Am J Gastroenterol 2007;102:1483-1488.

97. Tack J, Caenepeel P, Arts J, Lee KJ, Sifrim D, Janssens J. Prevalence of acid reflux in functional dyspepsia and its association with symptom profile. Gut 2005;54:1370-1376.

98. Samsom M, Verhagen MA, vanBerge Henegouwen GP, Smout AJ. Abnormal clearance of exogenous acid and increased acid sensitivity of the proximal duodenum in dyspeptic patients. Gastroenterology 1999;116:515-520. 
99. Lee KJ, Demarchi B, Demedts I, Sifrim D, Raeymaekers P, Tack J. A pilot study on duodenal acid exposure and its relationship to symptoms in functional dyspepsia with prominent nausea. Am J Gastroenterol 2004;99:1765-1773.

100. Misra SP, Broor SL. Is gastric acid responsible for the pain in patients with essential dyspepsia? J Clin Gastroenterol 1990;12: 624-627.

101. Lambert JR. The role of Helicobacter pylori in nonulcer dyspepsia. A debate - for. Gastroenterol Clin North Am 1993;22:141-151.

102. Jaakkimainen RL, Boyle E, Tudiver F. Is Helicobacter pylori associated with non-ulcer dyspepsia and will eradication improve symptoms? A meta-analysis. BMJ 1999;319:1040-1044.

103. el-Omar E, Penman I, Ardill JE, McColl KE. A substantial proportion of non-ulcer dyspepsia patients have the same abnormality of acid secretion as duodenal ulcer patients. Gut 1995;36:534-538.

104. Sarnelli G, Cuomo R, Janssens J, Tack J. Symptom patterns and pathophysiological mechanisms in dyspeptic patients with and without Helicobacter pylori. Dig Dis Sci 2003;48:2229-2236.

105. Moayyedi P, Soo S, Deeks J, et al. Systematic review and economic evaluation of Helicobacter pylori eradication treatment for non-ulcer dyspepsia. BMJ 2000;321:659-664.

106. Laine L, Schoenfeld P, Fennerty MB. Therapy for Helicobacter pyloriin patients with nonulcer dyspepsia. A meta-analysis of randomized, controlled trials. Ann Intern Med 2001;134:361-369.

107. Miwa H, Hirai S, Nagahara A, et al. Cure of Helicobacter pylori infection does not improve symptoms in non-ulcer dyspepsia patients-a double-blind placebo-controlled study. Aliment Pharmacol Ther 2000;14:317-324.

108. Wong WM, Xiao SD, Hu PJ, et al. Standard treatment for Helicobacter pylori infection is suboptimal in non-ulcer dyspepsia compared with duodenal ulcer in Chinese. Aliment Pharmacol Ther 2005;21:73-81.

109. Moayyedi P, Soo S, Deeks J, et al. Eradication of Helicobacter pylori for non-ulcer dyspepsia. Cochrane Database Syst Rev 2006;(2): CD002096.

110. Jin X, Li YM. Systematic review and meta-analysis from Chinese literature: the association between Helicobacter pylori eradication and improvement of functional dyspepsia. Helicobacter 2007;12:541546.

111. Mearin F, Perez-Oliveras M, Perello A, et al. Dyspepsia and irritable bowel syndrome after a Salmonella gastroenteritis outbreak: one-year follow-up cohort study. Gastroenterology 2005;129:98104.

112. $\mathrm{Li} \mathrm{X}$, Chen $\mathrm{H}, \mathrm{Lu} \mathrm{H}$, et al. The study on the role of inflammatory cells and mediators in post-infectious functional dyspepsia. Scand $\mathrm{J}$ Gastroenterol 2010;45:573-581.

113. Kindt S, Tertychnyy A, de Hertogh G, Geboes K, Tack J. Intestinal immune activation in presumed post-infectious functional dyspepsia. Neurogastroenterol Motil 2009;21:832-e56.

114. Tack J, Demedts I, Dehondt G, et al. Clinical and pathophysiological characteristics of acute-onset functional dyspepsia. Gastroenterology 2002;122:1738-1747.

115. Camilleri CE, Carlson PJ, Camilleri M, et al. A study of candidate genotypes associated with dyspepsia in a U.S. community. Am J Gastroenterol 2006;101:581-592.

116. Holtmann G, Siffert W, Haag S, et al. G-protein beta 3 subunit 825
CC genotype is associated with unexplained (functional) dyspepsia. Gastroenterology 2004;126:971-979.

117. Tahara T, Arisawa T, Shibata T, et al. Homozygous $825 \mathrm{~T}$ allele of the GNB3 protein influences the susceptibility of Japanese to dyspepsia. Dig Dis Sci 2008;53:642-646.

118. van Lelyveld N, Linde JT, Schipper M, Samsom M. Candidate genotypes associated with functional dyspepsia. Neurogastroenterol Motil 2008;20:767-773.

119. Oshima T, Nakajima S, Yokoyama T, et al. The G-protein beta3 subunit 825 TT genotype is associated with epigastric pain syndrome-like dyspepsia. BMC Med Genet 2010;11:13.

120. Arisawa T, Tahara T, Shibata T, et al. Genetic polymorphisms of molecules associated with inflammation and immune response in Japanese subjects with functional dyspepsia. Int $\mathrm{J}$ Mol Med 2007;20:717-723.

121. Tahara T, Arisawa T, Shibata T, Nakamura M, Wang F, Hirata I. COMT geneval158met polymorphism in patients with dyspeptic symptoms. Hepatogastroenterology 2008;5 5:979-982.

122. Tahara T, Arisawa T, Shibata T, et al. 779 TC of CCK-1 intron 1 is associated with postprandial syndrome (PDS) in Japanese male subjects. Hepatogastroenterology 2009;56:1245-1248.

123. Arisawa T, Tahara T, Shibata T, et al. Genetic polymorphisms of cyclooxygenase-1 (COX-1) are associated with functional dyspepsia in Japanese women. J Womens Health (Larchmt) 2008;17:10391043.

124. Tahara T, Shibata T, Wang F, et al. A genetic variant of the p22PHOX component of NADPH oxidase C242T is associated with reduced risk of functional dyspepsia in Helicobacter pylori-infected Japanese individuals. Eur J Gastroenterol Hepatol 2009;21: 1363-1368.

125. Tahara T, Shibata T, Nakamura M, et al. Homozygous TRPV1 $315 \mathrm{C}$ influences the susceptibility to functional dyspepsia. J Clin Gastroenterol 2010;44:e1-e7.

126. Watt AH, Lewis DJ, Horne JJ, Smith PM. Reproduction of epigastric pain of duodenal ulceration by adenosine. Br Med J (Clin Res Ed) 1987;294:10-12.

127. Rao SS, Mudipalli RS, Mujica V, Utech CL, Zhao X, Conklin JL. An open-label trial of theophylline for functional chest pain. Dig Dis Sci 2002;47:2763-2768.

128. Barbera R, Feinle C, Read NW. Nutrient-specific modulation of gastric mechanosensitivity in patients with functional dyspepsia. Dig Dis Sci 1995;40:1636-1641.

129. Pilichiewicz AN, Feltrin KL, Horowitz M, et al. Functional dyspepsia is associated with a greater symptomatic response to fat but not carbohydrate, increased fasting and postprandial CCK, and diminished PYY. Am J Gastroenterol 2008;103:2613-2623.

130. Feinle-Bisset C, Horowitz M. Dietary factors in functional dyspepsia. Neurogastroenterol Motil 2006;18:608-618.

131. Lee KJ, Kim JH, Cho SW. Dietary influence on electro-gastrography and association of alterations in gastric myoelectrical activity with symptoms in patients with functional dyspepsia. J Gastroenterol Hepatol 2006;21:59-64.

132. Chua AS, Bekkering M, Rovati LC, Keeling PW. Clinical efficacy and prokinetic effect of the CCK-A antagonist loxiglumide in nonulcer dyspepsia. Ann N Y Acad Sci 1994;713:451-453.

133. Carvalho RV, Lorena SL, Almeida JR, Mesquita MA. Food intol- 
erance, diet composition, and eating patterns in functional dyspepsia patients. Dig Dis Sci 2010;55:60-65.

134. Gonlachanvit S. Are rice and spicy diet good for functional gastrointestinal disorders? J Neurogastroenterol Motil 2010;16:131-138.

135. Hu ML, Wu KL, Chiu YC, Chiu KW, Changchien CS. Effect of ginger on patients with functional dyspepsia. J Gastroenterol Hepatol 2009;24(suppl 1):A31.

136. Feinle-Bisset C, Vozzo R, Horowitz M, Talley NJ. Diet, food intake, and disturbed physiology in the pathogenesis of symptoms in functional dyspepsia. Am J Gastroenterol 2004;99:170-181.

137. Gwee KA, Bak YT, Ghoshal UC, et al. Asian consensus on irritable bowel syndrome. J Gastroenterol Hepatol 2010;25:1189-1205.

138. Harvey RF, Mauad EC, Brown AM. Prognosis in the irritable bowel syndrome: a 5-year prospective study. Lancet 1987;1:963965.

139. Owens DM, Nelson DK, Talley NJ. The irritable bowel syndrome: long-term prognosis and the physician-patient interaction. Ann Intern Med 1995;122:107-112.

140. Haag S, Senf W, Tagay S, et al. Is there a benefit from intensified medical and psychological interventions in patients with functional dyspepsia not responding to conventional therapy? Aliment Pharmacol Ther 2007;25:973-986.

141. Zhang G, Li Y. Psychological intervention on improvement of depression emotion in patients with functional dyspepsia. Chin J Clin Rehabil 2006;10:160-161.

142. Sheu BS, Lin CY, Lin XZ, Shiesh SC, Yang HB, Chen CY. Long-term outcome of triple therapy in Helicobacter pylori-related nonulcer dyspepsia: a prospective controlled assessment. Am J Gastroenterol 1996;91:441-447.

143. Dhali GK, Garg PK, Sharma MP. Role of anti-Helicobacter pylori treatment in $\mathrm{H}$. pylori-positive and cytoprotective drugs in $\mathrm{H}$. pylori-negative, non-ulcer dyspepsia: results of a randomized, double-blind, controlled trial in Asian Indians. J Gastroenterol Hepatol 1999;14:523-528.

144. Hsu PI, Lai KH, Tseng HH, et al. Eradication of Helicobacter pylori prevents ulcer development in patients with ulcer-like functional dyspepsia. Aliment Pharmacol Ther 2001;15:195-201.

145. Ang TL, Fock KM, Teo EK, et al. Helicobacter pylori eradication versus prokinetics in the treatment of functional dyspepsia: a randomized, double-blind study. J Gastroenterol 2006;41:647-653.

146. Gwee KA, Teng L, Wong RK, Ho KY, Sutedja DS, Yeoh KG. The response of Asian patients with functional dyspepsia to eradication of Helicobacter pylori infection. Eur J Gastroenterol Hepatol 2009;21:417-424.

147. Fock KM, Katelaris P, Sugano K, et al. Second Asia-Pacific consensus guidelines for Helicobacter pylori infection. J Gastroenterol Hepatol 2009;24:1587-1600.

148. Correa P, Fontham ET, Bravo JC, et al. Chemoprevention of gastric dysplasia: randomized trial of antioxidant supplements and antiHelicobacter pylori therapy. J Natl Cancer Inst 2000;92:1881-1888.

149. Uemura N, Mukai T, Okamoto S, et al. Effect of Helicobacter pylori eradication on subsequent development of cancer after endoscopic resection of early gastric cancer. Cancer Epidemiol Biomarkers Prev 1997;6:639-642.

150. Mera R, Fontham ET, Bravo LE, et al. Long term follow up of patients treated for Helicobacter pylori infection. Gut 2005;54:
1536-1540.

151. You WC, Brown LM, Zhang L, et al. Randomized double-blind factorial trial of three treatments to reduce the prevalence of precancerous gastric lesions. J Natl Cancer Inst 2006;98:974-983.

152. Leung WK, Lin SR, Ching JY, et al. Factors predicting progression of gastric intestinal metaplasia: results of a randomised trial on Helicobacter pylori eradication. Gut 2004;53:1244-1249.

153. Zhou L, Sung JJ, Lin S, et al. A five-year follow-up study on the pathological changes of gastric mucosa after $H$. pylori eradication. Chin Med J (Engl) 2003;116:11-14.

154. Fuccio L, Zagari RM, Eusebi LH, et al. Meta-analysis: can Helicobacter pylori eradication treatment reduce the risk for gastric cancer? Ann Intern Med 2009;151:121-128.

155. Zhou L. Ten-year follow-up study on the incidence of gastric cancer and the pathological changes of gastric mucosa after $H$. pylori eradication in China. Gastroenterology 2008;134:A233.

156. Saito D, Boku N, Fujioka T, Fukuda Y. Impact of H. pylori eradication on gastric cancer prevention: endosopic results of the Japanese Intervention Trial (JITHP-Study). A randmized multi-center trial. Gastroenterology 2005;128:A4.

157. Wong BC, Lam SK, Wong WM, et al. Helicobacter pylori eradication to prevent gastric cancer in a high-risk region of China: a randomized controlled trial. JAMA 2004291:187-194.

158. Mahadeva S, Goh KL. Epidemiology of functional dyspepsia: a global perspective. World J Gastroenterol 2006;12:2661-2666.

159. Spechler SJ. Epidemiology and natural history of gastro-oesophageal reflux disease. Digestion 1992;51(suppl 1):24-29.

160. Locke GR 3rd, Talley NJ, Fett SL, Zinsmeister AR, Melton LJ 3rd. Prevalence and clinical spectrum of gastroesophageal reflux: a population-based study in Olmsted County, Minnesota. Gastroenterology 1997;112:1448-1456.

161. Quigley EM. Functional dyspepsia (FD) and non-erosive reflux disease (NERD): overlapping or discrete entities? Best Pract Res Clin Gastroenterol 2004;18:695-706.

162. Small PK, Loudon MA, Waldron B, Smith D, Campbell FC. Importance of reflux symptoms in functional dyspepsia. Gut 1995; 36:189-192.

163. Bolling-Sternevald E, Lauritsen K, Aalykke C, et al. Effect of profound acid suppression in functional dyspepsia: a double-blind, randomized, placebo-controlled trial. Scand J Gastroenterol 2002;37:1395-1402.

164. Blum AL, Arnold R, Stolte M, Fischer M, Koelz HR, The Frosch Study Group. Short course acid suppressive treatment for patients with functional dyspepsia: results depend on Helicobacter pylori status. Gut 2000;47:473-480.

165. Gerson LB, Triadafilopoulos G. A prospective study of oesophageal 24-h ambulatory $\mathrm{pH}$ monitoring in patients with functional dyspepsia. Dig Liver Dis 2005;37:87-91.

166. Peura DA, Kovacs TO, Metz DC, Siepman N, Pilmer BL, Talley $\mathrm{NJ}$. Lansoprazole in the treatment of functional dyspepsia: two double-blind, randomized, placebo-controlled trials. Am J Med 2004; 116:740-748.

167. Hengels $\mathrm{K}$. Therapeutic efficacy of $15 \mathrm{mg}$ lansoprazole mane in 269 patients suffering from non-ulcer dyspepsia (NUD): a multicentre, randomized, double-blind study. Gut 1998;43:A89.

168. Talley NJ, Lauritsen K. The potential role of acid suppression in 
functional dyspepsia: the BOND, OPERA, PILOT, and ENCORE studies. Gut 2002;50(suppl 4):iv36-iv41.

169. Wang WH, Huang JQ, Zheng GF, et al. Effects of proton-pump inhibitors on functional dyspepsia: a meta-analysis of randomized placebo-controlled trials. Clin Gastroenterol Hepatol 2007;5:178185.

170. Gwee KA, Hwang JE, Ho KY, Yeoh KG, Lum CF, Ang PK. In-practice predictors of response to proton pump inhibitor therapy in primary care patients with dyspepsia in an Asian population. J Clin Gastroenterol 2008;42:134-138.

171. Reimer C, Søndergaard B, Hilsted L, Bytzer P. Proton-pump inhibitor therapy induces acid-related symptoms in healthy volunteers after withdrawal of therapy. Gastroenterology 2009;137:80-87, 87.e1.

172. Niklasson A, Lindström L, Simrén M, Lindberg G, Björnsson E. Dyspeptic symptom development after discontinuationof a proton pump inhibitor: a double-blind placebo-controlled trial. Am J Gastroenterol 2010;105:1531-1537.

173. Lombardo L, Foti M, Ruggia $O$, Chiecchio A. Increased incidence of small intestinal bacterial overgrowth during proton pump inhibitor therapy. Clin Gastroenterol Hepatol 2010;8:504-508.

174. Hiyama T, Yoshihara M, Matsuo K, et al. Meta-analysis of the effects of prokinetic agents in patients with functional dyspepsia. $\mathrm{J}$ Gastroenterol Hepatol 2007;22:304-310.

175. Tack J, Masclee A, Heading R, et al. A dose-ranging, placebo-controlled, pilot trial of Acotiamide in patients with functional dyspepsia. Neurogastroenterol Motil 2009;21:272-280.

176. Matsueda K, Hongo M, Tack J, Aoki H, Saito Y, Kato H. Clinical trial: dose-dependent therapeutic efficacy of acotiamide hydrochloride (Z-338) in patients with functional dyspepsia - $100 \mathrm{mg}$ t.i.d. is an optimal dosage. Neurogastroenterol Motil 2010;22: 618-e173.

177. Qin F, Huang X, Ren P. Chinese herbal medicine modified xiaoyao san for functional dyspepsia: meta-analysis of randomized controlled trials. J Gastroenterol Hepatol 2009;24:1320-1325.

178. Tatsuta M, Iishi H. Effect of treatment with liu-jun-zi-tang (TJ-43) on gastric emptying and gastrointestinal symptoms in dyspeptic patients. Aliment Pharmacol Ther 1993;7:459-462.

179. Kusunoki H, Haruma K, Hata J, et al. Efficacy of rikkunshito, a traditional Japanese medicine (Kampo), in treating functional dyspepsia. Intern Med 2010;49:2195-2202.

180. Soo S, Forman D, Delaney BC, Moayyedi P. A systematic review of psychological therapies for nonulcer dyspepsia. Am J Gastroenterol 2004;99:1817-1822.

181. Mertz H, Fass R, Kodner A, Yan-Go F, Fullerton S, Mayer EA. Effect of amitriptyline on symptoms, sleep, and visceral perception in patients with functional dyspepsia. Am J Gastroenterol 1998; 93:160-165.

182. Dinan TG, Mahmud N, Rathore O, et al. A double-blind placebo-controlled study of buspirone-stimulated prolactin release in non-ulcer dyspepsia - are central serotoninergic responses enhanced? Aliment Pharmacol Ther 2001;15:1613-1618.

183. Chua A, Keating J, Hamilton D, Keeling PW, Dinan TG. Central serotonin receptors and delayed gastric emptying in non-ulcer dyspepsia. BMJ 1992;305:280-282.

184. Dinan TG, Yatham LN, Barry S, Chua A, Keeling PW. Serotonin supersensitivity: the pathophysiologic basis of non-ulcer dyspepsia? A preliminary report of buspirone/prolactin responses. Scand J Gastroenterol 1990;25:541-544.

185. Miwa H, Nagahara A, Tominaga K, et al. Efficacy of the 5-HT1A agonist tandospirone citrate inimproving symptoms of patients with functional dyspepsia: a randomized controlled trial. Am J Gastroenterol 2009;104:2779-2787.

186. van Kerkhoven LA, Laheij RJ, Aparicio N, et al. Effect of the antidepressant venlafaxine in functional dyspepsia: a randomized, double-blind, placebo-controlled trial. Clin Gastroenterol Hepatol 2008;6:746-752.

187. Wu CY, Chou LT, Chen HP, Chang CS, Wong PG, Chen GH. Effect of fluoxetine on symptoms and gastric dysrhythmia in patients with functional dyspepsia. Hepatogastroenterology 2003;50: 278-283.

188. Tanum L, Malt UF. Personality traits predict treatment outcome with an antidepressant in patients with functional gastrointestinal disorder. Scand J Gastroenterol 2000;35:935-941.

189. Kang JY, Tay HH, Guan R. Chronic upper abdominal pain: site and radiation in various structural and functional disorders and the effect of various foods. Gut 1992;33:743-748.

190. Pilichiewicz AN, Horowitz M, Holtmann GJ, Talley NJ, Feinle-Bisset C. Relationship between symptoms and dietary patterns in patients with functional dyspepsia. Clin Gastroenterol Hepatol 2009;7:317-322.

191. Feinle-Bisset C, Meier B, Fried M, Beglinger C. Role of cognitive factors in symptom induction following high and low fat meals in patients with functional dyspepsia. Gut 2003;52:1414-1418.

192. Feinle C, Meier O, Otto B, D'Amato M, Fried M. Role of duodenal lipid and cholecystokinin A receptors in the pathophysiology of functional dyspepsia. Gut 2001;48:347-355.

193. Feinle C, Fried M. Duodenal sensitivity to lipids and gastric motility: contribution to functional dyspepsia. Praxis (Bern 1994) 1998;87:1817-1820.

194. Tsai SC, Hsieh JF, Ho YJ, Kao CH. Effects of butter and soybean oils on solid-phase gastric emptying in patients with functional dyspepsia. Abdom Imaging 2000;25:35-37.

195. Barbera R, Feinle C, Read NW. Abnormal sensitivity to duodenal lipid infusion in patients with functional dyspepsia. Eur J Gastroenterol Hepatol 1995;7:1051-1057.

196. Mullan A, Kavanagh P, O'Mahony P, Joy T, Gleeson F, Gibney MJ. Food and nutrient intakes and eating patterns in functional and organic dyspepsia. Eur J Clin Nutr 1994;48:97-105. 